\title{
Reduced presynaptic vesicle stores mediate cellular and network plasticity defects in an early-stage mouse model of Alzheimer's disease
}

Shreaya Chakroborty', Evan S. Hill², Daniel T. Christian', Rosalind Helfrich', Shannon Riley ${ }^{1}$, Corinne Schneider ${ }^{1}$, Nicolas Kapecki ${ }^{1}$, Sarah Mustaly-Kalimi ${ }^{1}$, Figen A. Seiler ${ }^{3}$, Daniel A. Peterson ${ }^{1}$, Anthony R. West ${ }^{1}$, Barbara M. Vertel ${ }^{2,3}$, William N. Frost ${ }^{2}$ and Grace E. Stutzmann ${ }^{1 *}$ (D)

\begin{abstract}
Background: Identifying effective strategies to prevent memory loss in AD has eluded researchers to date, and likely reflects insufficient understanding of early pathogenic mechanisms directly affecting memory encoding. As synaptic loss best correlates with memory loss in $A D$, refocusing efforts to identify factors driving synaptic impairments may provide the critical insight needed to advance the field. In this study, we reveal a previously undescribed cascade of events underlying pre and postsynaptic hippocampal signaling deficits linked to cognitive decline in AD. These profound alterations in synaptic plasticity, intracellular $\mathrm{Ca}^{2+}$ signaling, and network propagation are observed in 3-4 month old 3xTg-AD mice, an age which does not yet show overt histopathology or major behavioral deficits.

Methods: In this study, we examined hippocampal synaptic structure and function from the ultrastructural level to the network level using a range of techniques including electron microscopy (EM), patch clamp and field potential electrophysiology, synaptic immunolabeling, spine morphology analyses, 2-photon $\mathrm{Ca}^{2+}$ imaging, and voltagesensitive dye-based imaging of hippocampal network function in 3-4 month old 3xTg-AD and age/background strain control mice.

Results: In 3xTg-AD mice, short-term plasticity at the CA1-CA3 Schaffer collateral synapse is profoundly impaired; this has broader implications for setting long-term plasticity thresholds. Alterations in spontaneous vesicle release and paired-pulse facilitation implicated presynaptic signaling abnormalities, and EM analysis revealed a reduction in the ready-releasable and reserve pools of presynaptic vesicles in CA3 terminals; this is an entirely new finding in the field. Concurrently, increased synaptically-evoked $\mathrm{Ca}^{2+}$ in CA1 spines triggered by LTP-inducing tetani is further enhanced during PTP and E-LTP epochs, and is accompanied by impaired synaptic structure and spine morphology. Notably, vesicle stores, synaptic structure and short-term plasticity are restored by normalizing intracellular $\mathrm{Ca}^{2+}$ signaling in the AD mice.

(Continued on next page)
\end{abstract}

\footnotetext{
* Correspondence: grace.stutzmann@rosalindfranklin.edu

'Department of Neuroscience, The Chicago Medical School; The Center for Neurodegenerative Disease and Therapeutics, Rosalind Franklin University of Medicine and Science, 3333 Green Bay Rd, North Chicago, IL 60064, USA Full list of author information is available at the end of the article
}

(c) The Author(s). 2019 Open Access This article is distributed under the terms of the Creative Commons Attribution 4.0 International License (http://creativecommons.org/licenses/by/4.0/), which permits unrestricted use, distribution, and reproduction in any medium, provided you give appropriate credit to the original author(s) and the source, provide a link to the Creative Commons license, and indicate if changes were made. The Creative Commons Public Domain Dedication waiver (http://creativecommons.org/publicdomain/zero/1.0/) applies to the data made available in this article, unless otherwise stated. 


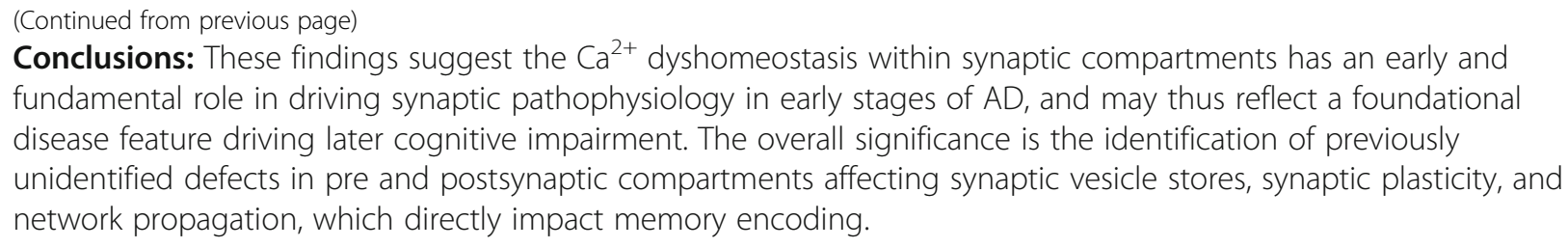

Keywords: Synaptic, Hippocampus, Short-term plasticity, Synaptic vesicles, Calcium, Ryanodine receptor, Patch clamp, 2-photon imaging, Electron microscopy, Network imaging, Mouse model, Spines, Alzheimer's disease

\section{Background}

Research on the etiology of Alzheimer's disease (AD) and cause of memory decay in AD has long focused on advanced histological hallmarks of aging and disease such as amyloid and tau aggregations. Yet, increasing evidence indicates that defects in synaptic structure and function play an earlier role in AD-associated memory decline [1-4]. This makes intuitive sense, as synapses are the initiating sites of most forms of memory encoding. Altered hippocampal long-term plasticity (LTP), one of the cellular correlates of learning and memory, has been well characterized across many AD mouse models at later disease stages, often concurrent with overt amyloid histopathology and memory impairments $[5,6]$. However, more subtle and insidious pathophysiological mechanisms are evident prior to these observations. To date, these remain insufficiently investigated and thus poorly understood. For example, hippocampal short-term plasticity (STP), which gates information processing and working memory, is often overlooked as a significant contributor to memory deficits in dementia. Post-tetanic potentiation (PTP), a form of presynaptic STP, is essential for setting LTP thresholds, synchronizing network propagation, and enabling short-term memory [7-9]. Many forms of STP are $\mathrm{Ca}^{2+}$ dependent [10] and thus, the early $\mathrm{Ca}^{2+}$ signaling abnormalities in $\mathrm{AD}$ can alter synaptic signaling and hippocampal network propagation. This can manifest as working memory deficits, consistent with those observed in 3-month old 3xTg-AD mice [11, 12].

While a substantial body of data characterizing longterm plasticity abnormalities in $\mathrm{AD}$ models exists, further investigation into upstream mechanisms is needed to understand causes of AD-linked memory loss. One of the earliest observed neuronal signaling alterations that directly associates with $\mathrm{AD}$ features and risk factors, such as amyloid and tau pathology, synaptic deficits, oxidative stress, and cell death, is intracellular $\mathrm{Ca}^{2+}$ dysregulation [2, 13-15]. Increased $\mathrm{Ca}^{2+}$ release through $\mathrm{IP}_{3} \mathrm{R}$ and RyR-localized ER channels occurs as early as 2 weeks of age in AD mouse models [16, 17], is observed in cells from FAD patients [18-20], and is $2-10$ fold greater than control responses within dendrites and spines [21, 22]. Synaptic compartments are particularly vulnerable to dysregulated RyR-Ca ${ }^{2+}$ signaling, and can result in impaired dendritic structure and function [23-25], altered presynaptic vesicle release properties [26], and synaptic plasticity deficits, all of which play key roles in memory processes [27-31]. A deeper investigation into these proximal components, such as the state of presynaptic neurotransmitter vesicle stores and the $\mathrm{Ca}^{2+}$ microenvironment is still needed. For example, increased spontaneous vesicle release activity occurs with PTP and derives from increased $\mathrm{Ca}^{2+}$ within terminals [32-34]. Alterations in these variables compromise the strength and fidelity of PTP, and thus interfere with LTP gating within individual synapses and across networks.

Here, we conducted a detailed study into early structural and functional hippocampal synaptic abnormalities, from the ultrastructural to network levels, in 3 month old $\mathrm{AD}$ mice to pinpoint early mechanisms of memory loss. We reveal a maladaptive cascade in $3 x T g-A D$ mice that includes impaired STP, reduced vesicle content in presynaptic active zones, aberrant meta-plasticity in dendritic $\mathrm{Ca}^{2+}$ responses, and spatially and temporally blunted network plasticity in the stratum oriens (SO) CA1 subfield. Our findings expose profound changes that emerge prior to the overt proteinopathy and associative memory deficits that define $\mathrm{AD}$, and offer new perspectives on mechanisms to prioritize for $\mathrm{AD}$ therapeutics.

\section{Methods \\ Mouse models}

Three to four-month old male and female 3xTg-AD mice $\left(\mathrm{PS}_{\mathrm{M} 146 \mathrm{~V}}, \mathrm{APP}_{\mathrm{SWE}}, \mathrm{Tau}_{\mathrm{P} 301 \mathrm{~L}} ;[6]\right.$ and age-matched background strain controls (C57bl6/J9) were used in this study. The 3xTg-AD mouse model was chosen for several reasons. For example, this mouse model has been extensively used and characterized for over 15 years, with over 600 PubMed citations. Furthermore, we have observed a highly consistent phenotype over time which likely reflects the PS1 KI gene $[6,17,22]$, and deficits in PS function and the associated $\mathrm{Ca}^{2+}$ dysregulations are applicable to both familial and sporadic AD [35]. While the field has noted a delay in the onset of amyloid and tau histopathology, we have obtained mice from the original cohort that maintains the histopathology pattern as described in [6]. 


\section{Hippocampal slice preparation}

Mice were deeply anesthetized with isoflurane, decapitated, and the brains dissected into ice-cold sucrose cutting solution (SCS, in mM: 200 sucrose, $1.5 \mathrm{KCl}, 0.5$ $\mathrm{CaCl}_{2}, \quad 4.0 \quad \mathrm{MgCl}_{2}, \quad 1.0 \quad \mathrm{KH}_{2} \mathrm{PO}_{4}, 25 \mathrm{NaHCO}_{3}, 10$ $\mathrm{Na}$-ascorbate and 20 dextrose, equilibrated with 95\% $\mathrm{O}_{2} / 5 \% \mathrm{CO}_{2}$.) Transverse hippocampal slices $(300 \mu \mathrm{m}$ for whole-cell patch clamp recordings and $400 \mu \mathrm{m}$ for VSD imaging) were prepared on a Camden Instruments vibratome with the chamber filled with ice-cold SCS and then transferred to a holding chamber where they were maintained at $30^{\circ} \mathrm{C}$ in standard artificial cerebrospinal fluid (aCSF, in mM: $130 \mathrm{NaCl}, 2.5 \mathrm{KCl}, 2.0 \mathrm{CaCl}_{2}, 1.2 \mathrm{MgSO}_{4}$, $1.25 \mathrm{KH}_{2} \mathrm{PO}_{4}, 25 \mathrm{NaHCO}_{3}$ and 10 dextrose) bubbled continuously with $95 \% \mathrm{O}_{2} / 5 \% \mathrm{CO}_{2}, \mathrm{pH} 7.3-7.4$, for at least $1 \mathrm{~h}$ before use.

\section{Whole cell patch clamp recording}

Hippocampal brain slices $(300 \mu \mathrm{m})$ were placed in a perfusion chamber mounted on a movable stage assembly on an upright microscope (BX50WI; Olympus Optical) and superfused at $2 \mathrm{ml} / \mathrm{min}$ with aCSF equilibrated with $95 \% \mathrm{O}_{2} / 5 \% \mathrm{CO}_{2}$ at room temperature $\left(27^{\circ} \mathrm{C}\right)$. Patch pipettes $(4-5 \mathrm{M} \Omega$ ) pulled from borosilicate glass tubing were filled with intracellular solution (in mM: 135 K-gluconate, $2 \mathrm{MgCl}_{2}$, 4 Na-ATP, $0.4 \mathrm{Na}$-GTP, $10 \mathrm{Na}-$ phosphocreatine and 10 HEPES, pH adjusted to 7.3 with $\mathrm{KOH})$ and $100 \mu \mathrm{M}$ bis-fura-2. Hippocampal CA1 pyramidal neurons were identified visually via IR-DIC optics, and electrophysiologically by their membrane properties and spike frequency accommodation. Membrane potentials and evoked responses were obtained in currentclamp mode using pClamp 10 software acquired at 10 $\mathrm{kHz}$ with a Digidata 1322 A-D converter and MultiClamp 700B amplifier. The current-voltage relationship was assessed by measuring voltage responses to constant current pulses of $500 \mathrm{~ms}$ duration and varying amplitudes from -200 to $+200 \mathrm{pA}$ in steps of $20 \mathrm{pA}$. Spontaneous postsynaptic potentials (sEPSPs) were recorded for $1 \mathrm{~min}$. Synaptic responses were evoked by stimulating the Schaffer collateral/commissural pathway with a monopolar stimulating electrode. Input/Output (I/O) curves were generated using stimulus intensities from 0 to $500 \mathrm{pA}$ in steps of $50 \mathrm{pA}$. Baseline stimulus intensity was determined from I/O curves as the stimulus intensity evoking a $30 \%$ of maximal response. Plasticity was induced by a tetanus consisting of two $100 \mathrm{~Hz}$ trains, 10 $\mathrm{s}$ apart. Paired pulse facilitation (PPF) was assessed before and after tetanus using interstimulus intervals of 25 , 50 and $200 \mathrm{~ms}$. Five successive responses were recorded for each interstimulus interval at $0.05 \mathrm{~Hz}$. To ensure slice viability and stable recording conditions within and between slices, membrane input resistance, membrane potential, AP waveform and amplitude, and electrode access resistance were continually monitored throughout the experiment; cells were used for recording only if the access resistance was maintained $<10 \mathrm{M} \Omega$, and all other parameters remained stable.

\section{$\mathrm{Ca}^{2+}$ imaging}

Imaging of fluorescent $\mathrm{Ca}^{2+}$ signals was performed in acute hippocampal brain slices using a custom-made video-rate multiphoton imaging system [36]. Individual CA1 pyramidal neurons were filled with the $\mathrm{Ca}^{2+}$ indicator bis-fura-2 via a patch pipette and $\mathrm{Ca}^{2+}$ responses imaged from dendrites and dendritic spines. Laser excitation was provided by $80 \mathrm{MHz}$ trains of ultra-short $(100 \mathrm{fs})$ pulses at $780 \mathrm{~nm}$ from a titanium/sapphire laser (Mai Tai Broadband, Spectra-Physics). The laser beam was scanned by paired galvanometers to provide a full-frame scan rate of $30 \mathrm{~Hz}$. The scanned beam was focused onto the tissue through an Olympus 40X water immersion objective (NA 0.8). Emitted fluorescence light was detected by a wide-field photomultiplier (R5929, Hamamatsu) and captured by frame-grabber software VideoSavant 5.0 (IO Industries). Imaging was synced with electrophysiological protocols through Digidata 1322 A-D board controlled by pClamp 10 software. $30 \mathrm{~Hz}$ trains were administered at baseline stimulus intensity. Images were analyzed offline with MetaMorph v7.8.6.0 software.

\section{Voltage sensitive dye imaging}

Hippocampal slices $(400 \mu \mathrm{m})$ were used for imaging experiments. Slices were equilibrated with $95 \% \mathrm{O}_{2} / 5 \% \mathrm{CO}_{2}$ in aCSF, as described above. The VSD RH 155 dye was bath applied at a concentration of $0.03 \mathrm{mg} / \mathrm{ml}$ (in aCSF) for 1.5 to $2 \mathrm{~h}$. Imaging was performed in dye-free aCSF. Schaffer collateral fibers were stimulated with a monopolar stimulating electrode using the stimulus intensity that evoked $50 \%$ of the maximal optical response in CA1 $(200-400 \mu \mathrm{A}, 100 \mu \mathrm{s})$. Synaptic plasticity was induced at baseline intensity by a tetanus consisting of two $100 \mathrm{~Hz}$ trains, $10 \mathrm{~s}$ apart. Optical responses were acquired with a RedShirtImaging CMOS camera with $128 \times 128$ pixels and a sampling rate of $1250 \mathrm{~Hz}$. Optical data were band-pass filtered $(125 \mathrm{~Hz} \mathrm{LP}, 1 \mathrm{~Hz} \mathrm{HP})$, and signals were divided by the resting light intensity at each pixel to yield measurements of DI/I using Neuroplex software. For spread analysis, a $6 \times 6$ binning was used to increase the signal-to-noise ratio of the optical responses. Data were analyzed offline using a custom MATLAB script to measure the amplitude of each trace, to identify the bin with the maximal response and calculate the percentage of bins above $50 \%$ of the maximal response. The range of color bar was set to strongest responding pixel or bin and the cut off for the color bar was set at 50\%. For duration analysis the time from 10 to $10 \%$ of the peak (rise and fall) of the optical response was calculated. 
Data were assessed for significance using repeated measures two-way ANOVAs with Student-Newman-Keuls post hoc analysis in SigmaPlot 11.

\section{Transmission Electron microscopy}

Mice were deeply anesthetized with halothane, and transcardially perfused with ice-cold modified Karnovsky's $2 \%$ paraformaldehyde and $2.5 \%$ glutaraldehyde, followed by immersion fixation in the same fixative for 7 days. Hippocampal sections of 3xTg-AD mice and NonTg controls were blocked in $200 \mu \mathrm{m}$ sections trimmed to the CA1 SR subfield, followed by further fixation and dehydration as described previously [37]. Sections were then flat embedded in epoxy resin between two sheets of Aclar Fluorohalocarbon film [38]. After polymerization, sections of the CA1 SR subfield were cut using a Leica EMUC6 ultramicrotome, stained with uranyl acetate and lead citrate and imaged using a JEOL JEM-1230 transmission electron microscope equipped with a Hamamatsu ORCA-HR CCD Camera (AMT XR-60 imaging system). Excitatory asymmetric synapses within the CA1 SR subfield were focused upon, as these constitute the major glutamatergic Schaffer collateral inputs from the CA3 subfield [39, 40], and this approach allows us to align the ultrastructural data with our electrophysiological and synaptic $\mathrm{Ca}^{2+}$ imaging data. Electron micrographs at a magnification of 30,000X were analyzed using ImageJ software to measure post synaptic density length and number of vesicles in the readily releasable, reserve and resting pools in each group, as described [41]. Experimenters were blind to mouse strain.

\section{Dantrolene treatment and dose schedule}

A nanocrystal formulation of dantrolene, Ryanodex (Lyotropic Therapeutics Inc.) was administered intraperitoneally at $10 \mathrm{mg} / \mathrm{kg}$ [42] to $3 \times \mathrm{Tg}$ - AD and NonTg mice. Mice were injected daily for 4 weeks starting at 2 months of age. Control 3xTg-AD and NonTg mice were administered $0.9 \%$ saline daily.

\section{Dendritic spine imaging}

Mice were transcardially perfused with cold $1 \%$ paraformaldehyde in phosphate-buffered saline (PBS, pH 7.4) for $1 \mathrm{~min}$, followed by cold $4 \%$ paraformaldehyde with $0.125 \%$ glutaraldehyde in PBS for $12 \mathrm{~min}$. Brains were extracted and post-fixed in the same fixative for $12 \mathrm{~h}$. Coronal hippocampal sections $200 \mu \mathrm{m}$ thick were cut from the fixed brains. Hippocampal sections were floated in $1 \mathrm{X}$ PBS in a glass petri dish with a clear glass slide glued to the bottom. The section was secured on the slide with a nitrocellulose membrane and metal washers. The hippocampal CA1 subfield was visualized through a cut out segment of the nitrocellulose membrane.
Sharp electrodes were pulled from glass capillaries and filled with a $5 \%(100 \mathrm{mM})$ Lucifer Yellow (LY) solution. The solution was visualized at $4 \mathrm{X}$ magnification with ultraviolet illumination. Electrodes were placed into the tissue and systematically moved on a diagonal through the thickness of the brain section. When the membrane of a CA1 neuron was pierced, the LY solution was allowed to passively diffuse into the soma and proximal dendritic arbor, allowing visualization of the neuron. Injection of a constant negative current $(1-5 \mathrm{nA})$ was then delivered to allow robust filling of the entire dendritic arbor [43, 44]. Electric current was ceased at the first sign of LY leak from the injection site (typically $1-3 \mathrm{~min}$ ) and the electrode removed from the soma. Single electrodes were re-used to fill multiple cells throughout the CA1 subfield. The filled neurons were spaced apart so that there was no overlap of filled dendritic arbors. Sections with LY-filled neurons were mounted in Vectashield mounting medium (Vector Laboratories) on slides with a $120 \mu \mathrm{m}$ spacer (Electron Microscopy Sciences), coverslipped and sealed for imaging. All slides were stored at $4{ }^{\circ} \mathrm{C}$.

\section{Immunohistochemistry}

(see [28] for further details.) Mice were deeply anesthetized with urethane $(1.5 \mathrm{~g} / \mathrm{kg})$ and then transcardially perfused with ice-cold buffered saline followed by $4 \%$ paraformaldehyde. Brains were extracted and post-fixed for $12-24 \mathrm{~h}$, then cut on a Leica SM 2010R sliding microtome at $40 \mu \mathrm{m}$ thickness. Free-floating hippocampal sections were washed with TBS $+0.3 \%$ Triton-X $(3 \times$ 5 minutes). Sections were blocked with $0.3 \%$ Triton-X + $10 \%$ Goat serum for $1 \mathrm{~h}$ and then incubated in primary antibody (PSD-95,1:500, Cell Signaling, catalogue number $2507 \mathrm{~S}$ ) diluted in $1 \%$ Goat serum $+0.1 \%$ Triton-X + TBS for $24 \mathrm{~h}$ at $4{ }^{\circ} \mathrm{C}$. The sections were washed again with TBS $+0.1 \%$ Tween $(3 \times 5 \mathrm{~min})$ and incubated in secondary antibody at 1:500 dilution (Alexa Fluor 488 conjugated to IgG goat anti-rabbit antibody, Invitrogen \# A11008) diluted in 1\% Goat serum+ 0.1\% Triton-X + TBS for $1 \mathrm{~h}$. Sections were washed in TBS $+0.01 \%$ Tween $(3 \times 5 \mathrm{~min})$. Sections were then incubated in primary antibody (Synaptophysin,1:300, Cell Signaling, catalogue number D35E4) diluted in $1 \%$ Goat serum+ $0.1 \%$ Triton-X $+\mathrm{TBS}$ for $24 \mathrm{~h}$ at $4{ }^{\circ} \mathrm{C}$. The sections were washed again with TBS $+0.1 \%$ Tween $(3 \times 5 \mathrm{~min})$ and incubated in secondary antibody at 1:500 dilution (Alexa Fluor 594 conjugated to IgG goat anti-rabbit antibody, Abcam \# Ab150080) diluted in 1\% Goat serum+ 0.1\% Triton-X + TBS for $1 \mathrm{~h}$.

Sections were stained in 1:5000 DAPI diluted in $0.1 \mathrm{M}$ PBS for $5 \mathrm{~min}$, then washed in TBS for $5 \mathrm{~min}$ and mounted and coverslipped with PVA-DABCO for microscopy. Confocal images were obtained and analyzed using a 60X objective lens on an Olympus Fluoview 
confocal microscope. MetaMorph software (v.7) was used to quantify the \% staining density of fluorescently labeled synaptophysin, PSD-95, and their colocalization, over a threshold intensity level for a region of the CA1 $\mathrm{SR}$, as described in http://www.bioimagingsolutions.com /MolDev/metamorph_analysis.html.

\section{Data analysis and statistics}

Evoked responses were analyzed offline using Clampfit 10 and Graphpad Prism 6 software. For PTP recordings, data were recorded $0-2 \mathrm{~min}$ post-tetanus, and for e-LTP, 15-20 min post-tetanus. Evoked EPSPs were averaged and expressed as a percentage of the average slope from pre-tetanus baseline recordings. For PPR analysis, EPSP amplitudes $(\mathrm{mV})$ were expressed as a ratio of the second EPSP over the first EPSP. MiniAnalysis (version 6.0.9, Synaptosoft) was used to measure sEPSP events with minimal amplitude of $0.2 \mathrm{mV}$ and minimal area of 3 $\mathrm{mV} * \mathrm{~ms}$. Baseline was determined from a $1 \mathrm{~ms}$ average immediately prior to each event using 'complex peak detection' in MiniAnalysis. Data were expressed as \pm SEM and assessed for significance using paired t tests, or one/ two-way ANOVAs with Tukey or Student-Newman-Keuls post hoc analysis, where $\mathrm{n}$ denotes number of neurons in whole-cell patch clamp experiments or number of slices in LFP and VSD experiments. For all experiments, $n=8-$ 10 neurons/slices for each group; power analysis was conducted on Statview to confirm sample size. Six to eight mice were used for each set of experiments.

\section{Results}

\section{Impaired short-term synaptic plasticity in 3xTg-AD CA1} neurons

Based on known abnormalities in regulators of synaptic transmission and long-term plasticity in $\mathrm{AD}$ [21, 29, 45-48] we began by asking if analogous STP mechanisms are altered at early disease stages in the $3 \mathrm{xTg}-\mathrm{AD}$ mouse model. Ideally, this is a period in which successful therapeutic intervention may still be achievable.

STP modulates synaptic strength and efficacy, and has roles in working memory, cognition, information processing and decision making [49-52]. There are several forms of STP, each with distinct signatures and functions. Post-tetanic potentiation (PTP), which lasts for seconds to minutes post-tetanus, reflects changes in $\mathrm{Ca}^{2}$ ${ }^{+}$-dependent vesicle release probability, and is instrumental for stabilizing and modulating synaptic strength [53-55]. Early LTP (E-LTP) emerges 20 min post-tetanus and involves post-translational modification of existing proteins such as glutamate receptors and second messengers [56-58]. Paired pulse facilitation (PPF) reflects $\mathrm{Ca}^{2+}$-dependent presynaptic STP. For comparison, late-LTP initiated $60 \mathrm{~min}$ post-tetanus requires gene transcription and de novo protein synthesis $[59,60]$.
As measured by whole cell patch clamp recordings from CA1 neurons in hippocampal slices, PTP and E-LTP from Schaffer collateral stimulation were severely impaired in 3xTg-AD mice vs NonTg mice (Fig. 1a). In NonTg neurons, PTP levels were $14.21 \pm 4.9 \%$ over baseline $\left(\mathrm{F}_{(3,40)}=4.12, p=0.0123\right)$, while in 3xTg-AD neurons PTP was below baseline $(-3.48 \pm 2.9 \%$, Fig. 1a). Similarly, E-LTP was observed in NonTg CA1 neurons, but not in 3xTg-AD CA1 neurons $(24.18 \pm 1.2 \%$ vs. $4.72 \pm 1.8 \%$ over baseline, respectively; $\mathrm{F}_{(3,60)}=29.77, p<$ 0.0001). The implications for STP deficiency are substantial and impinge upon broader network signaling as well as the stability of long-term plasticity.

To investigate further at the local circuit level, extracellular field potential (fEPSP) recordings were used to measure STP in the CA1 stratum radiatum (SR) upon Schaffer collateral stimulation (Fig. 1b). While patch clamp recordings provide detailed information from single neurons, fEPSPs are sensitive to subthreshold signal integration and local network properties. This level of analysis reveals STP deficits in 3xTg-AD animals similar to those described through single neuron patch clamp recordings. It should be noted that the absolute magnitude of the responses between patch clamp and extracellular field potential recordings are on different scales since patch clamp responses are recorded in the soma of a single cell but generated in the dendrites and filtered by their cable properties, while field potential recordings are measured directly in the dendritic subfield and reflect ionic flux as measured in the extracellular space. In NonTg mice, PTP and E-LTP magnitudes were $105.99 \pm 9.2 \%$ and $52.96 \pm 3.9 \%$ over baseline, respectively, while PTP and E-LTP were blunted in 3xTg-AD mice (PTP: $63.18 \pm 8.4 \%$ over baseline, $\mathrm{F}_{(3,128)}=152.5, \quad p<0.0001 ; \quad$ E-LTP: $36.48 \pm 4.2 \%$ over baseline, $\left.\mathrm{F}_{(3,148)}=97.02, p<0.0001\right)$.

Several mechanisms may underlie this deficit. $\mathrm{Ca}^{2+}$ dysregulation was first considered since it is fundamental to STP encoding and an integral component of $\mathrm{AD}$ pathogenesis. Prior studies have shown that abnormal ER $\mathrm{Ca}^{2+}$ release in AD models is prevented with dantrolene formulations which serve as negative allosteric modulators of RyR-evoked $\mathrm{Ca}^{2+}$ release [28, 45, 61]. We used this approach to determine if normalized $\mathrm{Ca}^{2+}$ signals in Ryanodex (a nanocrystalized formulation of dantrolene)-treated 3xTg-AD mice restores STP expression [61]. Here, PTP is enhanced $(120.56 \pm 10.2 \%)$ and E-LTP restored $(100.94 \pm 2.1 \%$ over baseline, Fig. 1c) in Ryanodex-treated 3xTg-AD mice relative to treated controls (PTP: $p>0.05$; E-LTP: $\mathrm{F}_{(3,148)}=421.9, p<0.0001$ ). Ryanodex in NonTg mice had no effect on STP expression $(p>0.05)$, consistent with its lack of effect on $\mathrm{Ca}^{2+}$ release in NonTg mice [61]. 
A

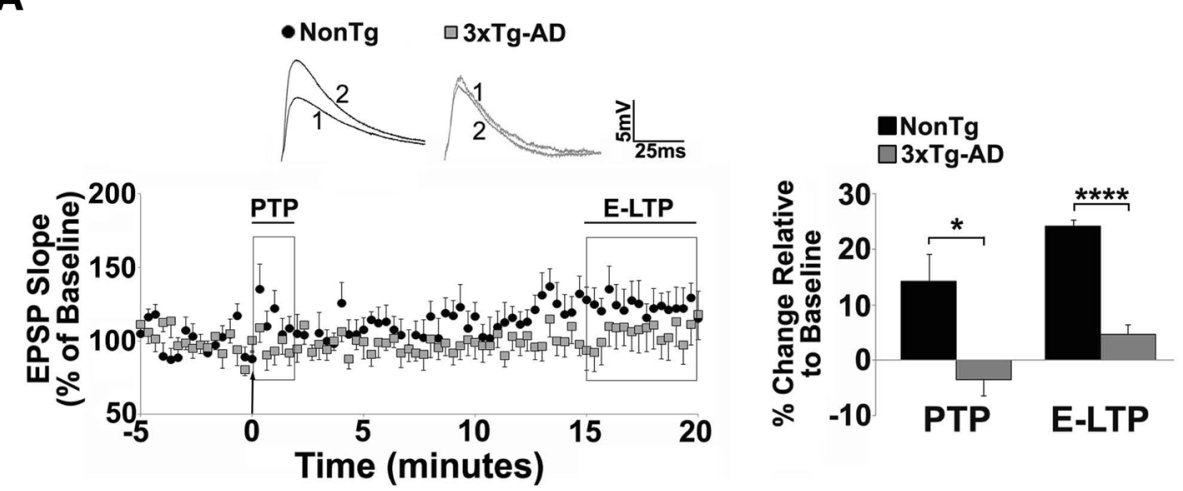

B
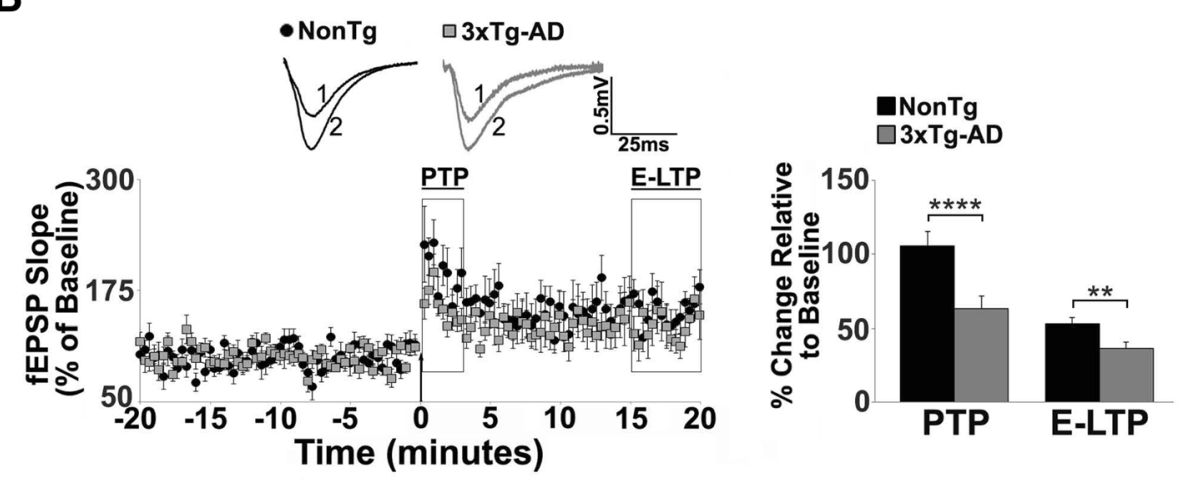

C
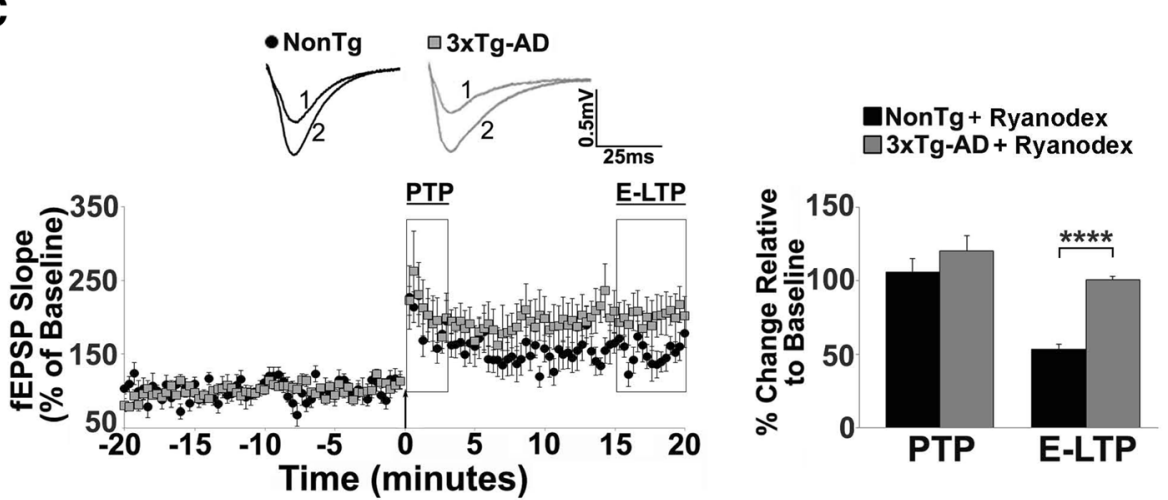

Fig. 1 Short term plasticity deficits in 3xTg-AD CA1 region reflect RyR-Ca ${ }^{2+}$ abnormalities. a-c Left: Graphs show averaged time course of Schaffer collateral-evoked synaptic responses from NonTg (black circles) and 3xTg-AD (gray squares) in the hippocampal region using (a) whole cell patch clamp from CA1 pyramidal neurons (NonTg $n=10$ neurons/6 mice; 3xTg-AD $n=10$ neurons/6 mice) and (b-c) extracellular field potential recordings in CA1 stratum radiatum (NonTg $n=8$ slices $/ 5$ mice; 3xTg-AD $n=8$ slices $/ 5$ mice). Right: Bar graphs show averaged \% change over baseline in the evoked response post-tetanus in 3xTg-AD (gray) compared to NonTg (black). Inset: Representative traces [1] before and [2] after tetanus from NonTg (black) and 3xTg-AD (gray) neurons. PTP and E-LTP are impaired in (a) individual neurons and (b) field potentials of 3xTg-AD CA1 neurons compared to NonTg neurons. c 30-day Ryanodex treatment restores or enhances PTP and E-LTP in 3xTg-AD CA1 circuits $(n=5$ slices $/ 5$ mice; NonTg $n=5$ slices $/ 5$ mice). The arrow denotes the time of tetanus. Data are presented as Mean \pm SEM; ${ }^{*} p<0.05,{ }^{* *} p<0.01$ and ${ }^{* * * *} p<0.0001$ represents significantly different from NonTg

These findings reinforce the role of intracellular $\mathrm{Ca}^{2+}$ signaling in generating STP, and demonstrate that increased RyR-mediated $\mathrm{Ca}^{2+}$ release blunts STP in young 3xTg-AD mice prior to overt cognitive deficits and histopathology. To identify the signaling mechanisms underlying this deficit, we combined anatomical, physiological, $\mathrm{Ca}^{2+}$ imaging and network imaging approaches to characterize presynaptic, postsynaptic and circuit level functions in the hippocampus of control and AD mouse models. This approach was designed to identify early mechanisms of memory decline in neurological disorders [62-64]. 


\section{Abnormal presynaptic function in the 3xTg-AD hippocampus \\ Increased spontaneous vesicle release}

Concomitant with PTP expression are changes in presynaptic spontaneous neurotransmitter release that manifests as an increase in the frequency of vesicle release in this form of plasticity $[65,66]$. Based on the STP defects in AD mice, we asked if the LTP-inducing tetanus differentially alters spontaneous excitatory postsynaptic potentials (sEPSP) properties in 3xTg-AD mice during PTP and E-LTP epochs. Again, there is a clear distinction in presynaptic release patterns between control and $\mathrm{AD}$ neurons (Fig. 2a-d, $\left.\mathrm{F}_{(3,23)}=7.09, p=0.0015\right)$. During PTP, sEPSP frequency is increased in NonTg CA1 neurons (Fig. 2a,c; paired $t_{(5)}=5.05, p=0.003$ ), consistent with the enhanced vesicle release probability that occurs during this plasticity phase. However, in 3xTg-AD neurons, there is no further enhancement in release frequency during PTP over baseline $(p>0.05)$, and sEPSP frequency is now similar between NonTg and 3xTg-AD neurons. During E-LTP, NonTg sEPSP frequency returned to pre-tetanus baseline, yet frequency remained elevated, similar to their baseline, in 3xTg-AD neurons $(2 \mathrm{~B}, \mathrm{C})$. Due to higher baseline spontaneous release in $3 x T g-A D$ mice, the lack of further post-tetanus increases can reflect a 'ceiling' effect on vesicle release due to enhanced $\mathrm{Ca}^{2+}$ leak in terminals and/or a reduction in vesicle pools. sEPSP amplitude did not differ between NonTg and 3xTg-AD neurons (Fig. 2d) during PTP or E-LTP, suggesting that postsynaptic mechanisms are not a prevailing mechanism here.

\section{Abnormalities in synaptically-evoked neurotransmitter release}

The increased spontaneous release and blunted potentiation during PTP at 3xTg-AD CA1 synapses indicate dominant presynaptic defects. To pursue this hypothesis, we investigated evoked presynaptic plasticity mechanisms and asked if PPF is altered at the CA3-CA1 synapse during PTP or E-LTP (Fig. 2e). Baseline (pre-tetanus) PPF (measured as the ratio of the 2nd response over the 1st) was similar between NonTg and 3xTg-AD mice at all interstimulus intervals (ISI; $25 \mathrm{~ms}, 50 \mathrm{~ms}$, and $200 \mathrm{~ms}$ ). At the $25 \mathrm{~ms}$ ISI, NonTg and 3xTg-AD animals showed similarly decreased PPF ratios relative to their own baselines during PTP (left; paired $\mathrm{t}_{(29)}=2.18, p=$ 0.037; $\mathrm{t}_{(29)}=2.77, p=0.009 ; \quad$ respectively); and E-LTP $\left(t_{(59)}=3.13, p=0.002\right.$, paired $t_{(38)}=3.11, p=0.01$, respectively), as would be expected under normal conditions of increased release probability and residual presynaptic $\mathrm{Ca}^{2+}$. Since increased release probability is positively associated with PTP expression [66], this manifests as a decrease in the paired pulse ratio [55, 67-69]. Consistent with this, in NonTg neurons, PPF ratios at the $50 \mathrm{~ms}$ interval were decreased during PTP and E-LTP $\left(\mathrm{t}_{(29)}=2.54, p=0.016 ; \mathrm{t}_{(59)}=2.54, p=0.01\right.$ respectively). However, in the 3xTg-AD neurons, PPF ratios at $50 \mathrm{~ms}$ ISI did not change during PTP or E-LTP relative to baseline, indicating unchanged vesicle release probability. At $200 \mathrm{~ms}$ ISI there were no changes in PPF ratios in either NonTg or 3xTg-AD CA1 neurons during PTP or E-LTP (data not shown), reflecting restoration of resting $\mathrm{Ca}^{2+}$ levels. Thus, for spontaneous and evoked activity, 3xTg-AD mice demonstrate abnormal $\mathrm{Ca}^{2}$ ${ }^{+}$-dependent presynaptic signaling and STP early in the disease process.

\section{Reduced presynaptic vesicle stores within active zones can account for synaptic plasticity deficits in $A D$}

Deficits in presynaptic plasticity can be attributed to a reduction in available neurotransmitter vesicles within active zones of CA3 terminals. Physiological events that align with this are enhanced presynaptic $\mathrm{Ca}^{2+}$ tone and associated excessive spontaneous vesicle release; conditions which are met in the $\mathrm{AD}$ mice $[28,29]$. To verify, electron microscopy (EM) studies were conducted to quantify dense core vesicles in CA3 terminals within the docked zone (within $50 \mathrm{~nm}$ from the presynaptic membrane), reserve zone (between 50 and $300 \mathrm{~nm}$ ), and resting pool (beyond $300 \mathrm{~nm}$ ), and postsynaptic density length (PSD) [41].

An important finding is that within the docked and reserve zones, 3xTg-AD mice had significantly fewer vesicles per terminal than NonTg mice $\left(\mathrm{F}_{(3,1546)}=63.2, p\right.$ $<0.001 ; \mathrm{F}_{(3,1191)}=62.0 ; p<0.001$; respectively), yet there were no differences among groups in the resting zone $\left(\mathrm{F}_{(3,1018)}=1.2 ; \quad p=0.3\right)$, suggesting that the depleted stores are restricted to the regions with a higher turnover that are actively engaged in release and recycling (Fig. 3c-d). Thus, in addition to increased vesicle release associated with increased $\mathrm{Ca}^{2+}$ tone, there is a likely deficit in replenishing stores in active zones, a function regulated by $\mathrm{RyR}-\mathrm{Ca}^{2+}$ [70-73]. This novel finding of reduced vesicle content in docked and reserve pools is sufficient to account for the synaptic plasticity and signaling deficits in $\mathrm{AD}$ mice, and may be one of the earliest features of synaptic pathophysiology described to date. Due to the known $\mathrm{Ca}^{2+}$-dependence on synaptic vesicle release and replenishment, we next asked if normalizing $\mathrm{RyR}-\mathrm{Ca}^{2+}$ signaling with 30-day Ryanodex treatment $(10 \mathrm{mg} / \mathrm{kg}$; i.p., [61]) would restore or increase the population of docked and reserve pools. As shown in Fig. $3 \mathrm{C} / \mathrm{D}$, this treatment increased vesicle numbers in the docked and reserve pools from the 3xTg-AD/Ryx group to the same levels as the NonTg/Ryx group (Scheffe post hoc analysis; $p=0.47$ and $p=0.99$, respectively). Furthermore, 3xTg-AD mice show shorter PSD lengths compared to NonTg mice $\left(\mathrm{t}_{(587)}=6.2, p<0.001\right)$, 
A

NonTg

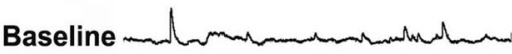

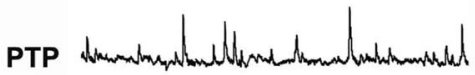

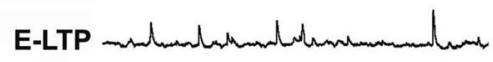

C

NonTg

$\square 3 \times T g-A D$

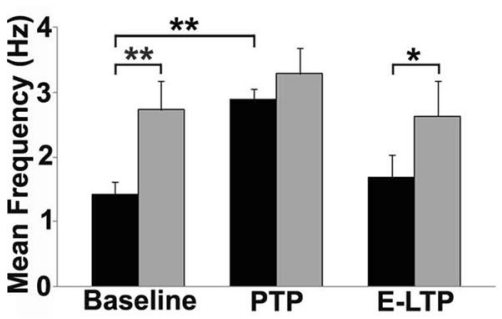

E

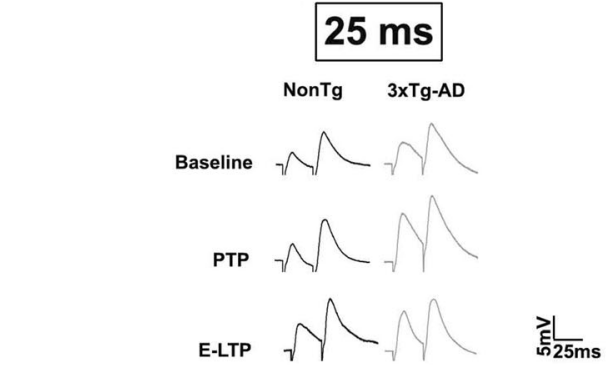

B 3xTg-AD

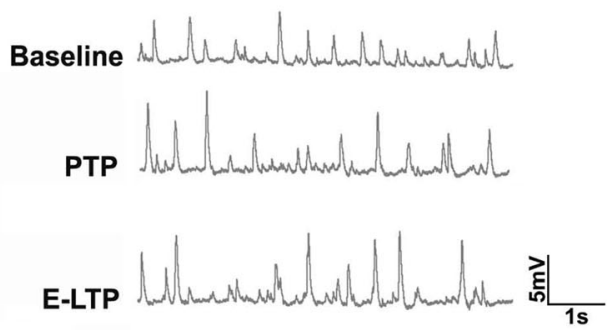

D

\section{DonTg \\ $\square$ 3xTg-AD}

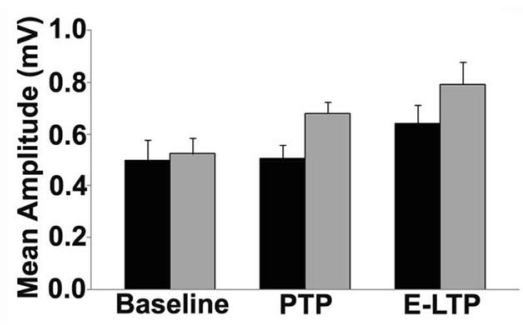

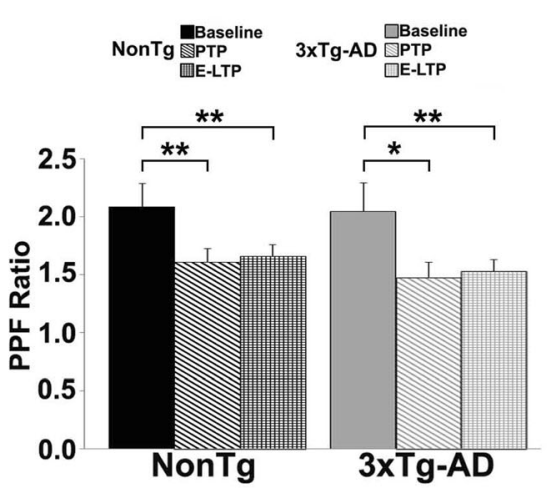
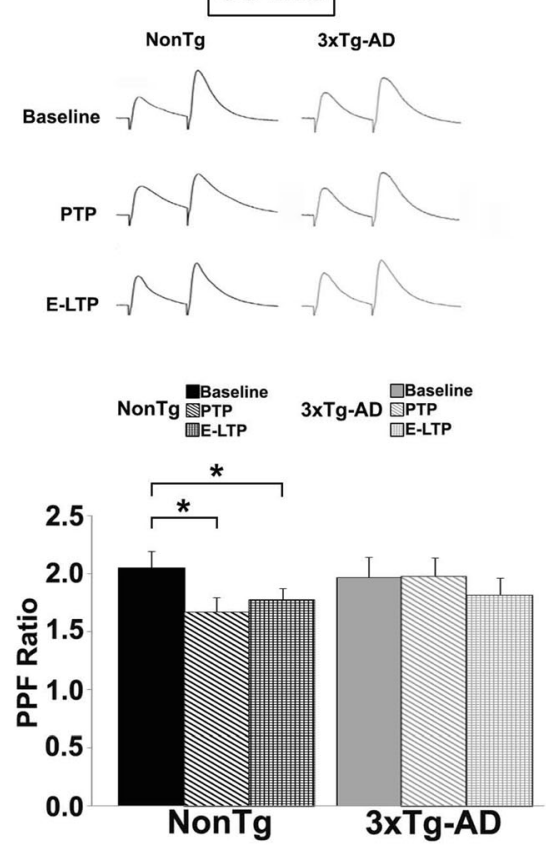

Fig. 2 Impaired spontaneous and evoked presynaptic release properties in 3xTg-AD mice. Representative traces of sEPSPs from (a) NonTg (black) and (b) 3xTg-AD (gray) CA1 neurons at baseline, PTP, and E-LTP time-points. c Bar graphs show elevated averaged sEPSP frequency in 3xTg-AD (gray) neurons compared to NonTg (black) at baseline, and remains elevated during PTP and E-LTP. In NonTg neurons, sEPSP frequency is increased during PTP relative to its baseline, and returns to baseline during E-LTP. $\mathbf{d}$ SEPSP amplitude is not significantly different between NonTg and 3xTg-AD neurons at all time-points. Data are presented as Mean $\pm \mathrm{SEM} ;{ }^{*} p<0.05$ and ${ }^{* *} p<0.01$ represents significantly different from NonTg, ${ }^{*}{ }^{\wedge} p<0.01$ represents significantly different from pre-tetanus baseline. e Bar graphs show averaged paired pulse ratio (PPR) responses during baseline, PTP and E-LTP at 25 ms ISI (left) and 50 ms ISI (right) from NonTg (black, and patterned black) and 3xTg-AD neurons (gray and patterned gray). At the $50 \mathrm{~ms}|S|$, the 3xTg-AD mice do not show the reduced PPR during PTP and E-LTP relative to baseline, as seen in the NonTg mice, suggesting that vesicle release probability is not further increased during these periods (NonTg $n=10$ neurons/6 mice; $3 \times \operatorname{Tg}-A D n=10$ neurons/ 6 mice). Insets: Representative traces from NonTg (black) and 3xTg-AD (gray) at $25 \mathrm{~ms}$ and $50 \mathrm{~ms}$. Data are presented as Mean \pm SEM; ${ }^{*} p<0.05$ and ${ }^{* *} p<0.01$ represent significantly different from pre-tetanus baseline 
A

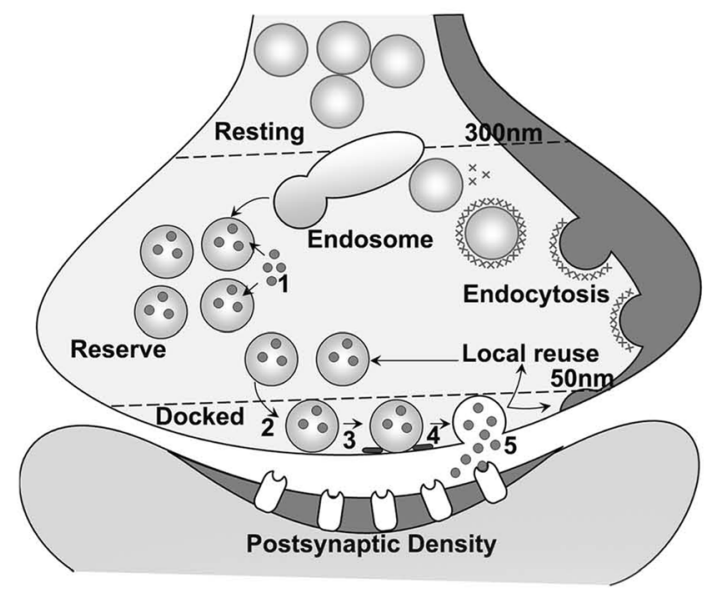

B

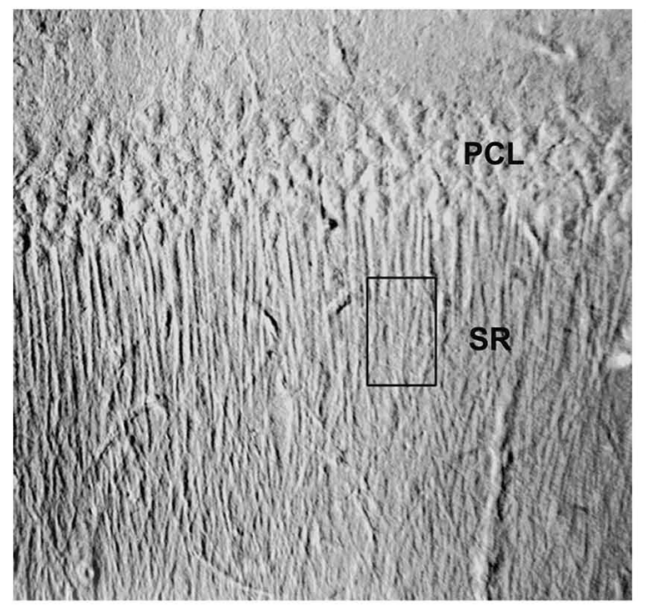

$3 \times \operatorname{Tg}$

C
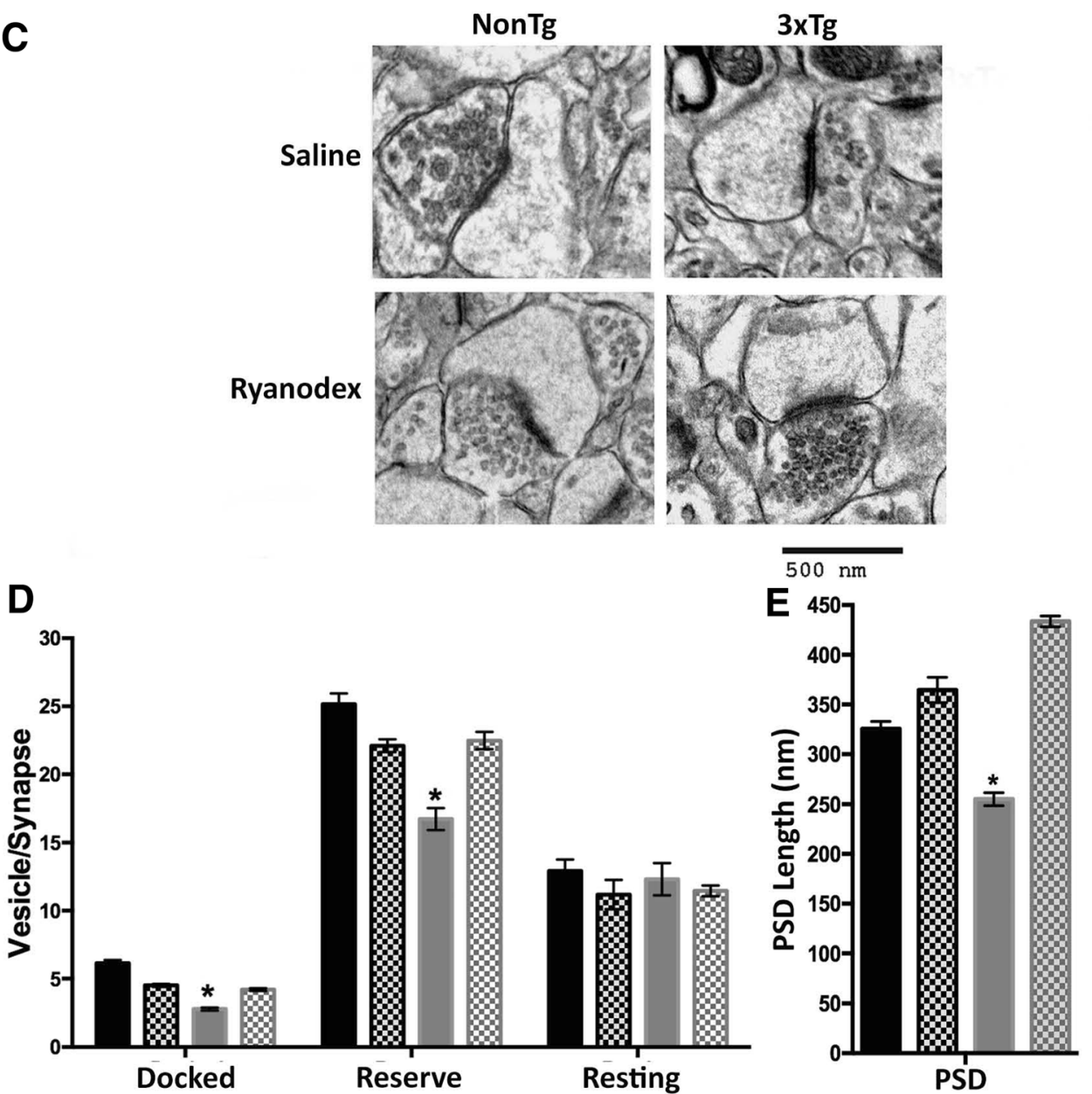

Fig. 3 3xTg-AD mice have fewer synaptic vesicles in active zones and decreased PSD length. a Diagram showing synaptic vesicle cycle including [1] neurotransmitter uptake, [2] docking, [3] priming, [4] fusion and [5] release, and vesicle classification based on distance from the presynaptic membrane (docked: 0-50 nm, reserve: $50-300 \mathrm{~nm}$, resting: $>300 \mathrm{~nm}$ ) [41]. b DIC image showing region of interest within the CA1 stratum radiatum (SR) from which ultrathin sections were obtained for EM; PCL: Pyramidal Cell Layer. c Representative electron micrographs from salineand Ryanodex-treated NonTg and 3xTg-AD asymmetric synapses (saline: NonTg $n=40$ micrographs/5 mice; $3 x T g-A D ~ n=56$ micrographs/7 mice. Ryanodex treated: NonTg $n=36$ micrographs/4 mice; 3xTg-AD $n=45$ micrographs/5 mice). Scale bar: 500 nm, direct magnification: 30,000X, PSD: Postsynaptic Density. Bar graphs comparing (d) number of synaptic vesicles per synapse and (e) PSD length observed in NonTg and 3xTg-AD mice. Data are presented as Mean \pm SEM; ${ }^{*} p<0.01$ represents significantly different from NonTg Sal group 
possibly reflecting a compensatory response to reduce excess postsynaptic stimulation related to increased sEPSP frequency (Fig. 3c, e). This pattern is also reversed in the $3 x \operatorname{Tg}-\mathrm{AD} / \mathrm{Ryx}$ treatment group, such that the PSD length is now greater than in the remaining groups ( $p<0.01$ for all comparisons). While the functional significance of this is under investigation, the discovery that the ultrastructure of the synapse and levels of presynaptic vesicle are altered in early stages of $\mathrm{AD}$, and show considerable reversal of deficits upon normalizing $\mathrm{RyR}-\mathrm{Ca}^{2+}$ signaling, demonstrates a highly plastic and potentially salvageable synaptic phenotype that may directly act to prevent the degenerative memory loss in $\mathrm{AD}$.

\section{Increased synaptically-evoked $\mathrm{Ca}^{2+}$ responses in 3xTg-AD CA1 dendrites}

Despite the fundamental role $\mathrm{Ca}^{2+}$ signaling plays in synaptic plasticity and memory encoding [74-76], $\mathrm{Ca}^{2+}$ responses generated during the tetanus or during STP have yet to be studied in cognitive disease models such as $\mathrm{AD}$. To address this, we used 2-photon $\mathrm{Ca}^{2+}$ imaging of fura-2 filled CA1 neurons to compare postsynaptic $\mathrm{Ca}^{2+}$ signals generated by an LTP-inducing tetanus $\left(2 \times 100 \mathrm{~Hz}, 10 \mathrm{~s}\right.$ apart) to determine if evoked $\mathrm{Ca}^{2+}$-signals are altered at critical plasticity-encoding epochs during $\mathrm{AD}$ pathogenesis.

Baseline postsynaptic $\mathrm{Ca}^{2+}$ responses in CA1 stratum radiatum were evoked by Schaffer collateral stimulation $(30 \mathrm{~Hz}, 1 \mathrm{~s}$ train). This stimulus generates stable physiological $\mathrm{Ca}^{2+}$ responses without altering vesicle release properties [21]. Evoked $\mathrm{Ca}^{2+}$ responses were measured at four time-points - pre-tetanus (baseline), during tetanus $(2 \times 100 \mathrm{~Hz}, 10 \mathrm{~s}$ apart), 1 min post-tetanus (PTP) and 20 min post-tetanus (E-LTP) (Fig. 4a). L-LTP (50-60 min after tetanus) responses were not measured due to potential washout of intracellular messengers. At each time-point, evoked $\mathrm{Ca}^{2+}$ responses were 3-4-fold greater in dendrites and spines of $3 \times \mathrm{Tg}-\mathrm{AD}$ neurons than in NonTg neurons (Fig. 4b-d, baseline: $\mathrm{F}_{(3,52)}=25.91$, tetanus: $\mathrm{F}_{(3,52)}=19.83$, PTP: $\mathrm{F}_{(3,52)}=16.55$, E-LTP: $\mathrm{F}_{(3,52)}=5.57, p<$ $0.001)$. In NonTg neurons, post-tetanus $\mathrm{Ca}^{2+}$ responses did not differ from baseline regardless of time-point; however in $3 x T g-A D$ neurons, $\mathrm{Ca}^{2+}$ responses steadily increased at each test point, with significance reached at E-LTP vs. baseline $\left(\mathrm{F}_{(1,64)}=39.34, p<0.0001\right)$. This augmentation suggests a $\mathrm{Ca}^{2+}$ signaling metaplasticity in the $\mathrm{AD}$ brain that is not normally present.

The $\mathrm{Ca}^{2+}$ and plasticity abnormalities in 3xTg-AD neurons appear activity-dependent, as there were no differences in passive membrane properties (resting membrane potential or input resistances), at baseline or post-tetanus ( $p>0.05$ for either strain). Voltage responses to injected current steps were also not different between
NonTg and 3xTg-AD neurons pre- or post-tetanus ( $p>0.05$ for either strain). Data not shown.

\section{Excessive dendritic $\mathrm{Ca}^{2+}$ responses mediate loss of mushroom spines and synaptic contacts in $A D$ hippocampal neurons}

Stable presynaptic-postsynaptic connections and mature dendritic spine architecture are necessary structural elements for proper plasticity encoding and expression. The structural stability of the presynaptic - postsynaptic microdomain is maintained through a variety of scaffold pathways largely involving adhesion molecules to stabilize synapses [77-79]. For example, $\mathrm{Ca}^{2+}$-regulated cell adhesion molecules, such as $\mathrm{N}$-cadherin, maintain the close junctions between pre and postsynaptic elements necessary for efficient synaptic communication and plasticity [80-82]. Stable spine formation associated with long term memory changes and synaptic efficacy is supported by actin cytoskeleton reconfiguration [83, 84]. $\mathrm{Ca}^{2+}$ dynamics within synaptic compartments play a key role in guiding structural fate [85-87] and are implicated in the loss of stable mushroom spines in neurons from AD mouse models [33, 88, 89]. Dendritic spines are not homogenous and are grouped as mushroom, thin, or stubby, each with distinct morphology and function. While thin spines are considered highly plastic, stubby spines are critical during postnatal development, and mushroom spines are relatively stable and incorporated into established neuronal networks and serve memory functions [37, 43, 79, 90].

Based on the steep increase in synaptically-evoked $\mathrm{Ca}^{2}$ ${ }^{+}$within spines of $3 \mathrm{xTg}-\mathrm{AD}$ mice, we asked if this affects the density and proportion of the varying spines types in CA1 neurons. We filled CA1 neurons from fixed hippocampal slices with Lucifer Yellow dye, generated 3D images using confocal microscopy and deconvolution software, and compared spine number and morphological type between the NonTg and AD mice [44, 91-93]. As previously described in older AD mice [94], we found a significant reduction in the total number of spines in younger $3 x T g-\mathrm{AD}$ mice $\left(\mathrm{F}_{(3,100)}=10.14 ; p<0.001\right)$, and a selective reduction in mushroom spines $\left(\mathrm{F}_{(3,100)}=8.3 ; p<\right.$ 0.001 ); the density of thin and stubby spines were not different $(p>0.05)$ (Fig. 5a). We next tested the role of $\mathrm{RyR}-\mathrm{Ca}^{2+}$ stores as an underlying mechanism driving the loss of the stable mushroom spines in mice treated with Ryanodex (as above). Consistent with previously described RyR-mediated synaptic deficits in $\mathrm{AD}$, the $3 x \mathrm{xg}-\mathrm{AD}$ mice treated with the negative allosteric RyR modulator had normal spine density and restored mushroom spine density (Fig. 5a). Notably, this treatment had no effect on the NonTg mice, suggesting this is not related to a general effect on mushroom spines, and speaks to normalization of an aberrant $\mathrm{Ca}^{2+}$ source. This is consistent with the 
A

Calcium Imaging Protocol:

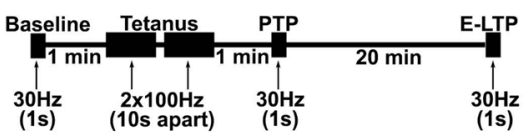

B
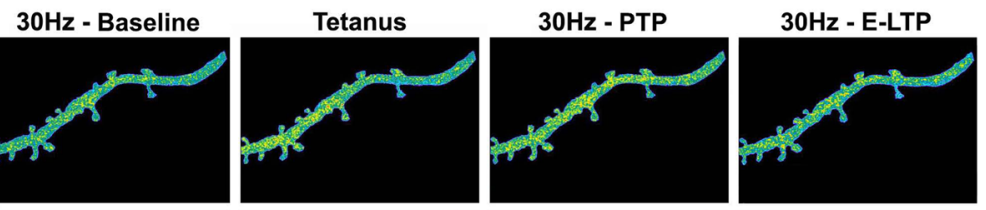

C

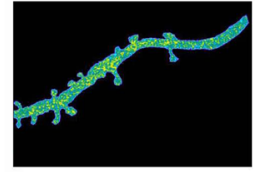

$3 \times T g-A D$
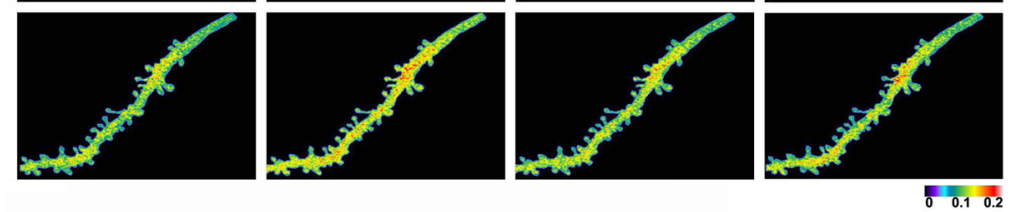

D

\section{$\square \mathbb{N}$ NonTg $\square \mathbb{N}$ 3xTg-AD}

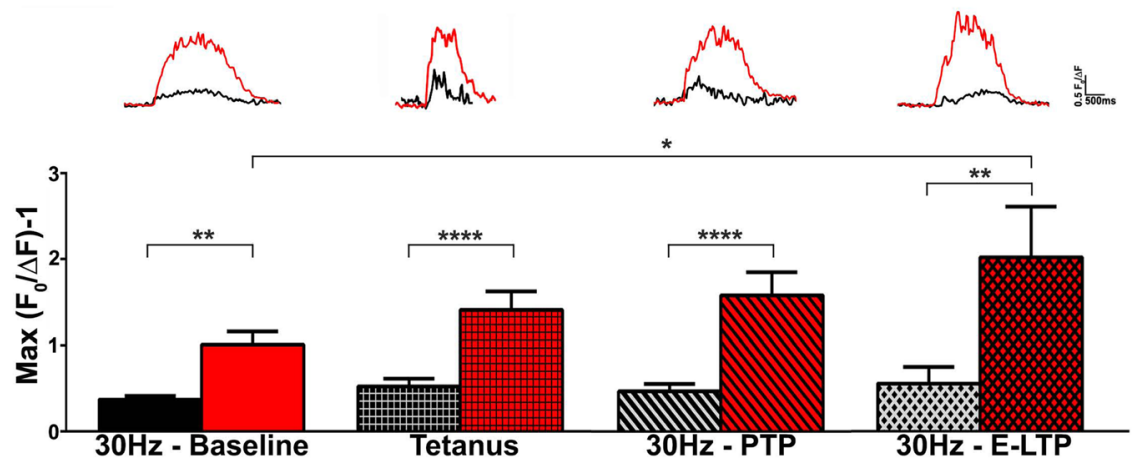

Fig. 4 Continuously increasing synaptically-evoked $\mathrm{Ca}^{2+}$ responses in 3xTg-AD CA1 neurons during and after tetanus. a Schematic showing the synaptic stimulation and $\mathrm{Ca}^{2+}$ imaging protocol. b-c Representative pseudocolored $\mathrm{Ca}^{2+}$ images of dendritic segments from (b) NonTg and (c) 3xTg-AD neurons at baseline, tetanus, PTP and E-LTP showing increased $\mathrm{Ca}^{2+}$ responses in 3xTg-AD neurons. Colors correspond to relative Ca ${ }^{2+}$ changes indicated by the bar below. (d) Bar graphs show increased $\mathrm{Ca}^{2+}$ responses in 3xTg-AD dendrites compared to NonTg at baseline, tetanus, PTP and E-LTP (NonTg $n=10$ neurons/6 mice; 3xTg-AD $n=10$ neurons/6 mice). Insets: Representative traces of $\mathrm{Ca}^{2+}$ responses from NonTg (black) and 3xTg-AD (red) dendrites. Data are presented as Mean \pm SEM; ${ }^{* *} p<0.01$ and ${ }^{* * *} p<0.0001$ represent significantly different from NonTg; ${ }^{*} p<0.05$ represents significantly different from pre-tetanus baseline

mechanism of action of Ryanodex, which restores normal function to leaky RyR, but has little effect on properly functioning channels [61].

The structural connectivity of synapses, as measured by the colocalization of fluorescently-labeled presynaptic and postsynaptic proteins (synaptophysin and PSD95, respectively) was examined in CA1 using immunohistochemical labeling and confocal microscopy (Fig. 5b). The density of each fluorophore was measured individually, and the degree of colocalization was measured to ascertain pre and postsynaptic components of synaptic pathology, and determine if there is a deficit in synaptic adhesion independent of synaptophysin and PSD95 levels. These analyses were conducted in saline-treated and Ryanodex-treated NonTg and 3xTg-AD mice to determine if deficits could be reversed by normalizing RyR-Ca ${ }^{2+}$ signaling. There was a significant decrease in synaptophysin density in the saline-treated 3xTg-AD mice only $\left(\mathrm{F}_{(3,72)}=5.7 ; p<0.01\right)$; Ryanodex-treated $3 \mathrm{xTg}$ AD mice demonstrated normal synaptophysin levels compared to NonTg controls $(p>0.05)$ where Ryanodex had no effect. The pattern was very similar for PSD95 staining, with a significant decrease in saline-treated $3 x T g-\mathrm{AD}$ mice $\left(\mathrm{F}_{(3,114)}=2.37 ; p<0.05\right)$ that was normalized with Ryanodex treatment. Perhaps most relevant, the density of colocalized synaptic proteins was significantly reduced in the saline-treated $3 \times \mathrm{Tg}$ - $\mathrm{AD}$ mice relative to $\operatorname{NonTg}\left(\mathrm{F}_{(3,90)}=2.5 ; p<0.05\right)$; Fig. $\left.5 \mathrm{~b}\right)$. As above, we questioned the role of $\mathrm{Ca}^{2+}$ dysregulation as a contributing factor in this deficit. In the Ryanodex-treated mice, we see a restoration of synaptic integrity, as well as normalized PSD95 and synaptophysin immunostaining levels in the 3xTg-AD mice, with no effects in NonTg mice. 
A
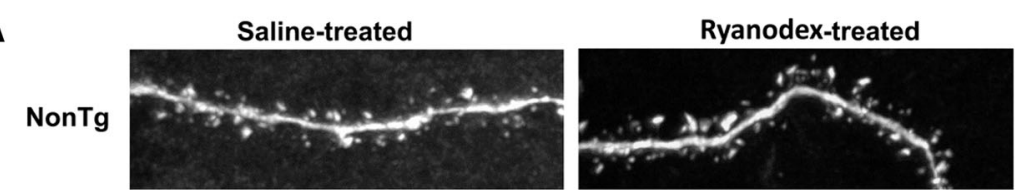

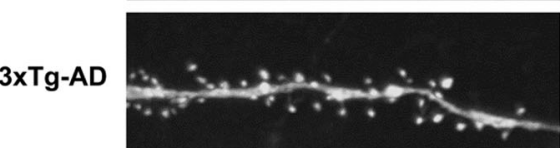

NonTg

口 Saline $\square$ Ryanodex

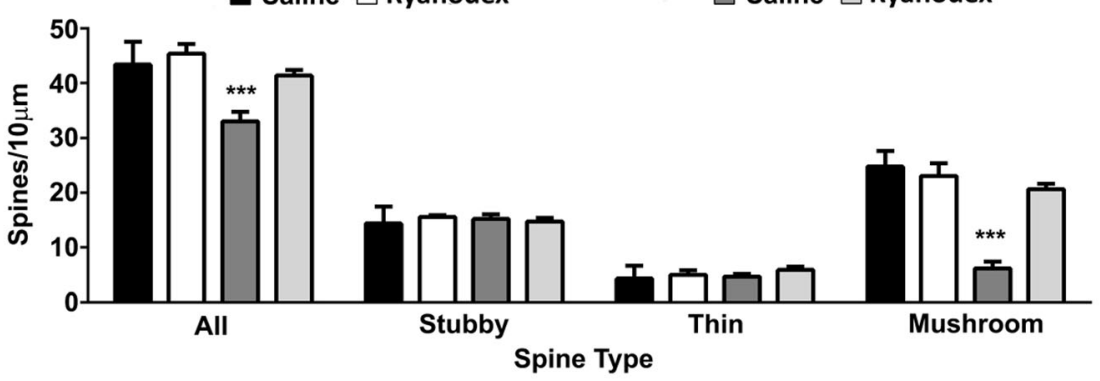

B

NonTg

PSD95
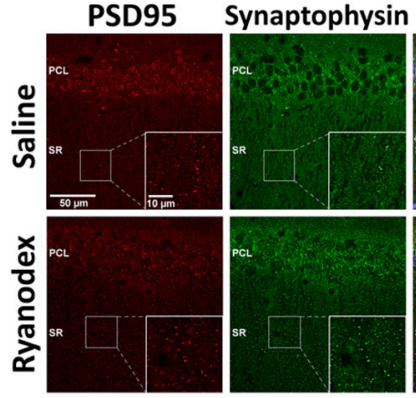

NonTg

- Saline $\square$ Dantrolene

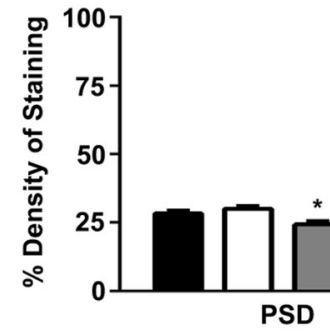

\section{$3 \times \operatorname{Tg}$}

PSD95 Synaptophysin Merged
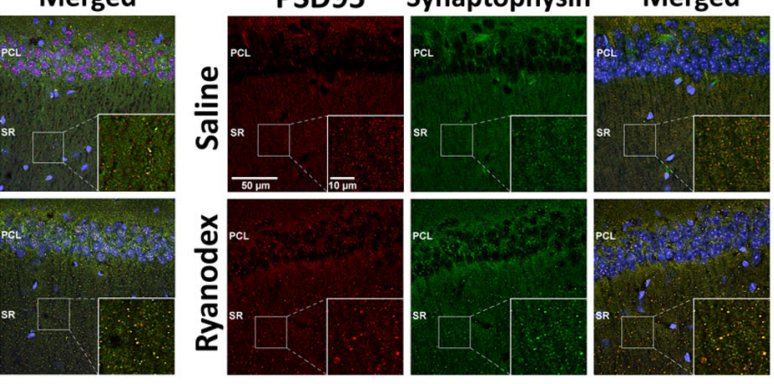

3xTg-AD $\square$ Saline $\square$ Dantrolene

Fig. 5 Loss of mushroom spines and synaptic integrity is reversed by normalized RyR-Ca ${ }^{2+}$ in $3 x T g-A D$ neurons. a Top: Images show Lucifer Yellow-filled dendrites and spines from saline- and Ryanodex-treated NonTg and 3xTg-AD CA1 neurons. Bottom: Bar graphs show a significant loss of mushroom spines in the 3xTg-AD mice, and a restoration of mushroom spine number after Ryanodex treatment in 3xTg-AD neurons. (Saline treated: NonTg $n=8$ neurons/3 mice; 3xTg-AD $n=6$ neurons/3 mice. Ryanodex treated: NonTg $n=4$ neurons $/ 3$ mice; $3 \times \operatorname{Tg}-\operatorname{AD} n=8$ neurons $/ 3$ mice; $2-5$ dendritic primary or secondary branches from each cell). $\mathbf{b}$ Top: Confocal images (40x, single plane, axial resolution $<0.3 \mu \mathrm{m})$ show colocalized immunolabeling of postsynaptic PSD (postsynaptic density, red) and presynaptic (synaptophysin, green) proteins at the CA3-CA1 synapses from saline- and Ryanodex-treated NonTg and 3xTg-AD mice. Inset: higher magnification (100x) detailing synaptic labeling patterns in each condition, with yellow fluorescence indicating close localization of pre- and postsynaptic markers in the merged images. Bottom: Bar graphs show a reduction of synaptophysin and PSD95 labelling, and colocalization of pre- and postsynaptic proteins in the saline-treated 3xTg-AD mice, and that Ryanodextreatment results in the recovery of these synaptic proteins in 3xTg-AD mice, and has no effects in the NonTg mice. (NonTg $n=36$ slices/6 mice for each treatment condition; 3xTg-AD $n=36$ slices/6 mice for each treatment condition). Data are presented as Mean \pm SEM; ${ }^{*} p<0.05,{ }^{* *} p<0.01$ and ${ }^{* * *} p<0.001$ represent significantly different from saline-treated 3xTg-AD 


\section{Defect in CA1 network plasticity identified in stratum oriens}

The above-described deficits reveal early and profound alterations in cellular and local circuit functions in $\mathrm{AD}$ models; however, to make more relevant links to cognitive decline, a broader examination of hippocampal network function is needed. Thus, wide-field VSD imaging approaches were used to determine if the cellular defects in 3xTg-AD mice translate to abnormal signal propagation across subfields of the Schaffer collateral CA1 network [95-97]. Although neural activity and glial responses contribute to VSD signals [98], VSD imaging is a powerful technique to monitor circuit activity across brain networks. In AD mouse models, VSD imaging has previously been used to examine signaling in the dentate gyrus [99], but to our knowledge, this is the first VSD study to examine AD-related CA1 network deficits in concert with electrophysiological and $\mathrm{Ca}^{2+}$ responses. Hippocampal slices were loaded with the VSD RH155 and spatial and temporal properties of depolarizing responses evoked by a single pulse to CA3 afferents were measured at baseline, PTP and E-LTP time points over the CA1 stratum radiatum (SR) and stratum oriens (SO) subfields (Fig. 6). There was no difference in the spatial properties of depolarization within the SR or SO between NonTg and 3xTg-AD mice at baseline, nor was there a difference post tetanus in the CA1 SR between NonTg and 3xTg-AD mice (Fig. 6b). However, when comparing pre- vs post-tetanus responses in the SO, only the NonTg mice demonstrated an increased spatial area of depolarization $\left(\mathrm{F}_{(2,12)}=5.06, p=0.015\right)$ at both the PTP and E-LTP time points $(p<0.01$ and $p<0.05$ respectively, Fig. 6a). In contrast, the lack of change in the SO depolarization area in $3 \mathrm{xTg}-\mathrm{AD}$ mice at these time points suggests blunted postsynaptic plasticity expression (Fig. 6a).

Given the Hebbian nature of hippocampal plasticity encoding, we also asked how the tetanus affects temporal properties of depolarizing synaptic responses in the CA1 subfield of NonTg and 3xTg-AD mice. Again, no significant changes were observed in SR during baseline, PTP or E-LTP in NonTg and 3xTg-AD mice (Fig. 6d). However, there was a significant increase in the duration of depolarizing responses in NonTg CA1 SO during PTP $\left(\mathrm{F}_{(2,12)}=3.72, p=0.039\right.$; Fig. 6c). There were no corresponding temporal increases in the 3xTg-AD SO (Fig. 6c). Thus, in the NonTg hippocampus we observed, post-tetanus, increased spatial and temporal properties of the CA1 response serving to promote Hebbian plasticity, synaptic potentiation and temporal summation in the CA1 SO region in NonTg mice. Since our electrophysiology and $\mathrm{Ca}^{2+}$ imaging experiments focused on SR, and not SO, these results were unexpected and present new opportunities to investigate sub-field specific deficits in plasticity encoding in $\mathrm{AD}$. Intriguingly, the SO may be a locus of network-level plasticity deficits in the earliest stages of AD.

\section{Discussion}

While preserving cognitive function is the 'holy grail' for AD therapeutics, the proximal mechanisms driving memory loss have remained elusive. Sustainable long-term memory encoding relies upon $\mathrm{Ca}^{2+}$-dependent short-term plasticity to establish synapse specificity and stably transform short-term into long-term memory through synaptic tagging and capture [7, 100]. RyR-evoked $\mathrm{Ca}^{2+}$ signaling plays a specific key role in the timing and strength of synaptic tagging; RyR activation during the tetanus increases the synaptic tag duration and durability, thus enabling LTP associativity; in contrast, if RyR channels are active prior to plasticity induction, as demonstrated in the $\mathrm{AD}$ models, the associative learning window is shortened and plasticity resilience is reduced $[8,101]$. Thus, one possibility suggested by the present study is that increased synaptic RyR activity weakens the critical tagging process needed for transforming and stabilizing long-term memory formation, resulting in impaired memory performance such as that observed in these 3xTg-AD mice at 3 months of age $[9,11,12]$. Notably, the ER-Ca ${ }^{2+}$ signaling abnormalities and memory deficits precede detectable amyloid and tau pathology in $\mathrm{AD}[17,31,45,102]$. Thus, we feel we have identified a critical plasticity signaling deficit during $\mathrm{AD}$ pathogenesis that has significant implications for memory formation (Fig. 7).

The increased synaptically-evoked $\mathrm{Ca}^{2+}$ responses described in young AD mice are especially pronounced within dendrites and spines, at a time and location where NMDA receptor activation triggers further RyRmediated $\mathrm{Ca}^{2+}$ release from ER stores [21, 29, 103]. These altered postsynaptic $\mathrm{Ca}^{2+}$ responses can initiate multiple pathogenic cascades, resulting in a range of defects from ultrastructural abnormalities to network propagation deficits, as detailed in this study. A critical new finding revealed here is the reduction in neurotransmitter vesicle stores within presynaptic active zones in the AD models, which is likely is associated with the increased spontaneous vesicle release resulting from enhanced $\mathrm{RyR}-\mathrm{Ca}^{2+}$ tone in terminals, and thus contributing to vesicle depletion. Under these compromised conditions, vesicle reserves are rapidly diminished during activity-demanding events such as a tetanus [28, 29] and contribute to weakened synaptic plasticity. While increased frequency of sEPSPs, synaptic depression mediated by excess $\mathrm{RyR}-\mathrm{Ca}^{2+}$, and presynaptic protein pathology in $\mathrm{AD}$ mouse models have previously been described [28, 45, 61], until now, functional presynaptic deficits were largely inferred. Here, ultrastructural analysis of synapses establishes that prodromal AD mice 
A

\section{-NonTg \\ $\square 3 x T g-A D$}

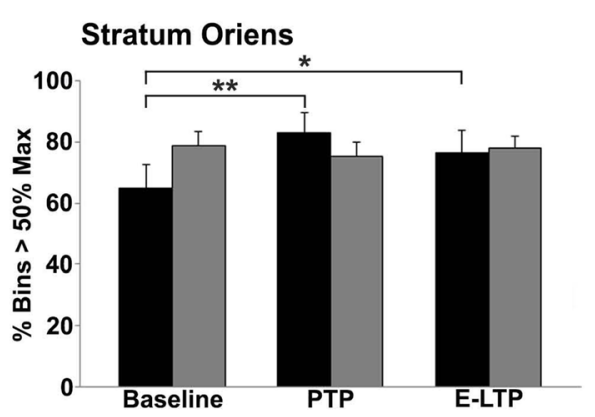

C

$$
\begin{aligned}
& \text { - NonTg } \\
& \square \text { 3xTg-AD }
\end{aligned}
$$

\section{Stratum Oriens}

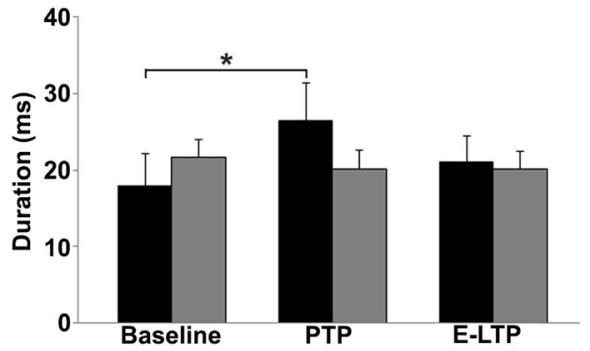

B

- NonTg

$\square 3 x T g-A D$

Stratum Radiatum

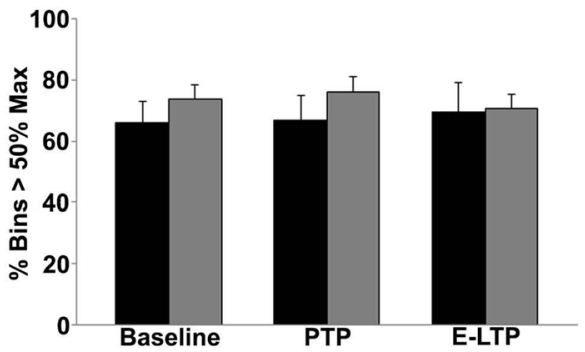

D

\section{- NonTg \\ $\square 3 x T g-A D$}

\section{Stratum Radiatum}

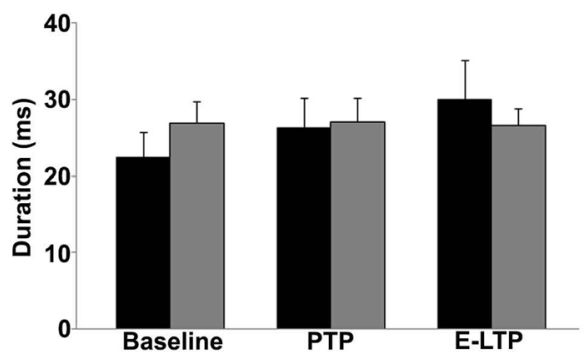

$\mathbf{E}$
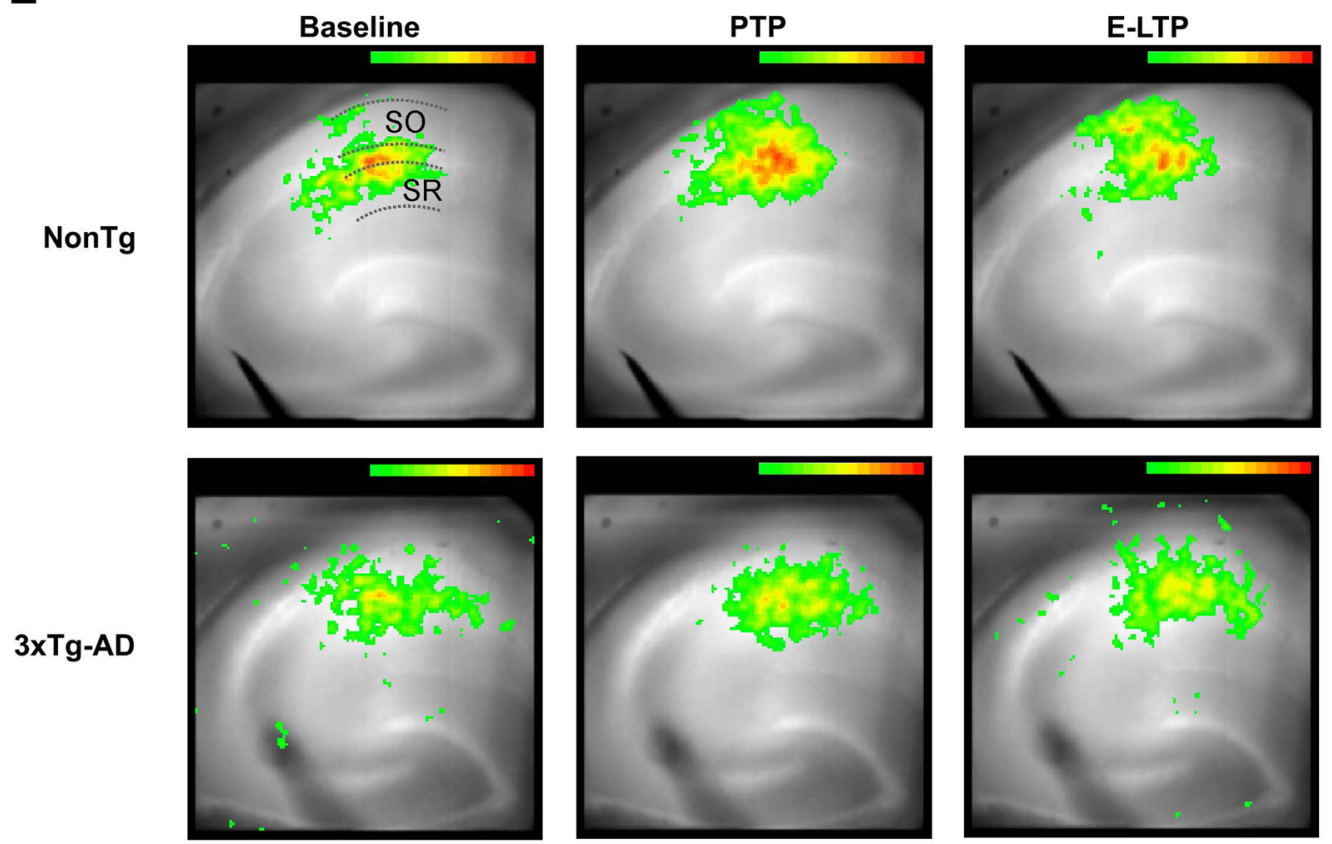

Fig. 6 Network-level STP deficits in the CA1 SO subfield of 3XTg-AD hippocampus. Bar graphs show spread (a-b) and duration (c-d) of strong depolarizing optical signals across the CA1 subfield in response to a single pulse to CA3 at baseline, PTP and E-LTP in the SO (a, c) and SR (b, d) from NonTg ( $n=9$ mice, 9 slices) and 3xTg-AD mice ( $n=11$ mice, 11 slices). There are no changes in spread or duration of optical signals in 3xTg-AD hippocampus after tetanus, compared to increased spread and duration of optical signals in NonTg hippocampus. e Pseudocolored VSD images showing the spread of optical signals in NonTg and 3xTg-AD hippocampus during baseline, PTP and E-LTP. The SO, SP, and SR regions are indicated by dashed lines in the NonTg/Baseline image. Optical signals $>50 \%$ over baseline are shown. Data presented as Mean \pm SEM; ${ }^{*} p<0.05$ and ${ }^{* *} p<0.01$ represent significantly different from pre-tetanus baseline 


\section{NORMAL}

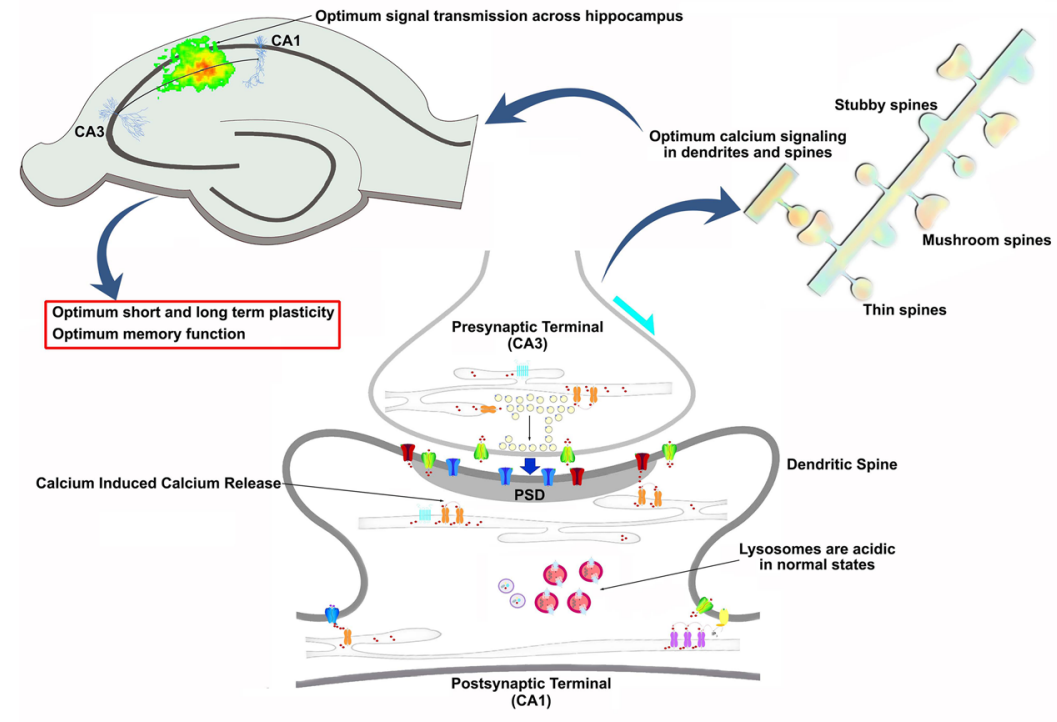

EARLY ALZHEIMER'S

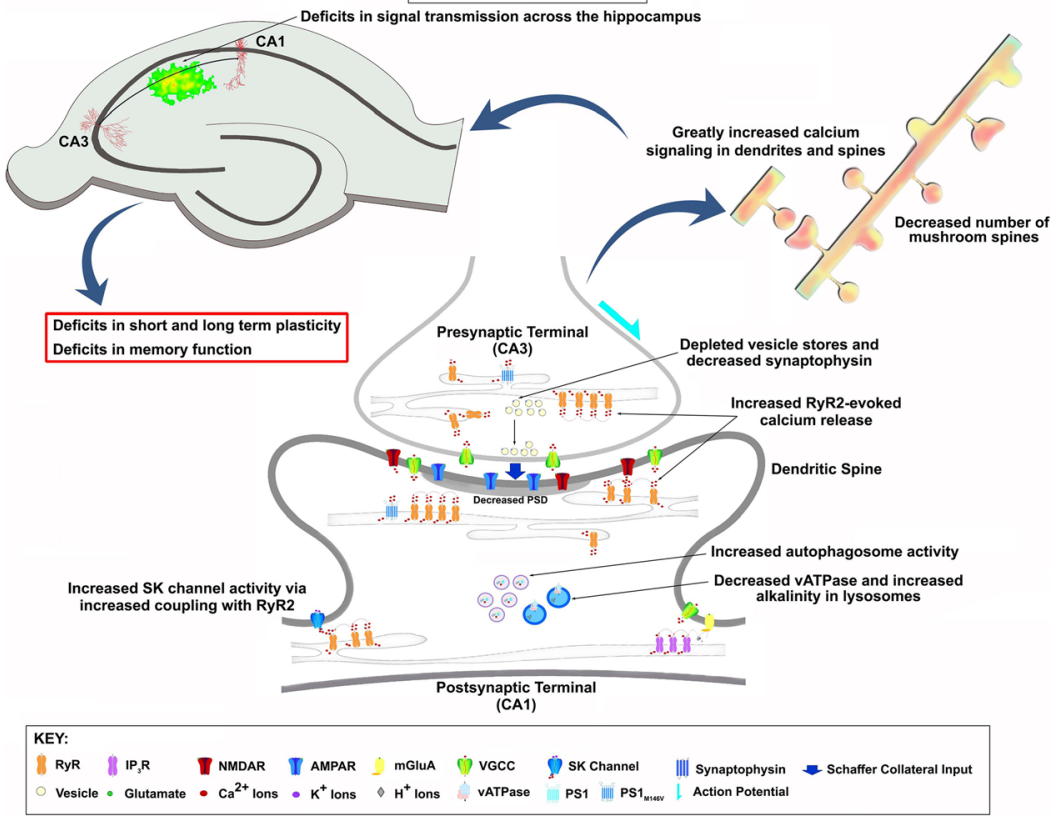

Fig. 7 Proposed role of RyR-Ca ${ }^{2+}$ signaling in early impairment of short term plasticity at the CA3-CA1 synapse in Alzheimer's disease. Normal: In presynaptic CA3 terminals, RyR-evoked $\mathrm{Ca}^{2+}$-Induced-Ca ${ }^{2+}$-Release (CICR) can trigger spontaneous neurotransmitter release. During high frequency activity (such as a train of action potentials), CICR is evoked by voltage-gated $\mathrm{Ca}^{2+}$ influx to increase residual $\mathrm{Ca}^{2+}$ levels and release probability. Postsynaptically, in CA1 terminals, NMDAR-mediated $\mathrm{Ca}^{2+}$ signals are amplified by RyR-CICR in dendritic spines, a phenomenon required for plasticity induction. In other plasticity pathways, the mGluA-PLC pathway generates $I P_{3}$, activating $I P_{3} R$. Activation of $I P_{3} R s$ produces regenerative $\mathrm{Ca}^{2+}$ waves that support plasticity and gene expression. RyR-Ca ${ }^{2+}$ also activates SK channels that modulate membrane excitability and frequency of action potential firing. Thus, optimum levels of $\mathrm{Ca}^{2+}$ signaling and synaptic plasticity proteins like synaptophysin and PSD in dendritic spines support maintenance of spine structure and signal transmission across the hippocampus, generating optimal levels of plasticity and normal memory function. Early AD: Presynaptically, increased RyR expression greatly increases CICR. Increased CICR alters vesicle cycling and cause depletion of vesicles from the readily releasable pool as well as the reserve pool. While this can be initially remedied by increasing neurotransmitter synthesis and vesicle cycling, such maladaptive mechanisms can potentially cause metabolic and oxidative stress leading to synapse loss. Postsynaptically, increased RyR-CICR can decrease PSD lengths and weaken synaptic integrity resulting in the loss of dendritic spines, specifically mushroom spines required for synaptic plasticity. Increased RyR-CICR can also increase SK channel activity which decreases neuronal excitability and increases threshold for induction of synaptic plasticity. Thus, greatly increased $\mathrm{Ca}^{2+}$ signaling and loss of proteins supporting synaptic plasticity result in the loss of synaptic integrity and dendritic mushroom spines and decreased signal transmission across the hippocampus. These results in early deficits in short and long term synaptic plasticity that ultimately causes memory impairments 
have reduced synaptic vesicle content within readily releasable and reserve pools. This new finding is consistent with readouts of presynaptic activity such as increased post-tetanic PPF ratios observed in these AD mice. PPF, a form of presynaptic $\mathrm{Ca}^{2+}$-dependent short-term plasticity, reflects the probability of neurotransmitter vesicle release, with increased ratios signifying a reduced release probability. The reduction in vesicle pools manifests as decreased PTP and synaptic strength at the single cell as well as local circuit levels in the AD mice. It has previously been shown that post-tetanic potentiation (PTP) correlates well with recruitment of synaptic vesicles from the reserve pool, thus PTP defects can be related to deficiencies in this specific population of vesicles $[104,105]$. Interestingly, the opposite pattern is described in a mouse model of Fragile X syndrome. Here, an enlargement of the ready releasable and reserve pools with enhanced vesicle recycling results in increased STP and synaptic excitability [106]. Each of these scenarios results in impaired cognitive functions, suggesting that precise regulation of vesicle dynamics is required for proper learning and memory processing.

Synapses with high release probability, such as the hippocampal Schaffer collateral synapse described in the 3xTg-AD and other AD mouse models, show greater depletion of synaptic vesicles [107]. Vesicle release probability (p) is inversely associated with PTP expression, and increases in (p) are associated with decreased PPF ratios $[55,67-69]$. This is consistent with the $\mathrm{Ca}^{2+}$-mediated increase in release probability, depleted presynaptic stores, and blunted PTP and network propagation described in the 3xTg-AD mice. Notably, synaptic strength is dependent upon the 3rd-4th power of $\left[\mathrm{Ca}^{2+}\right]$ [108], and this steep power function is a critical variable influencing plasticity defects in $\mathrm{AD}$ mice where synaptically-evoked $\mathrm{Ca}^{2+}$ levels within spines are 2-3 times higher than in controls [21, 103]. Under these extreme conditions, the markedly increased $\mathrm{Ca}^{2+}$ does not translate into stronger synaptic functions, but rather, creates a deficient or overtaxed synaptic environment. Furthermore, the elevated $\mathrm{Ca}^{2+}$ is positioned to drive structural deficits within spines, and destabilize prepostsynaptic integrity. The structural integrity of synapses, defined operationally as a stable pre-postsynaptic alignment through proteins such as adhesion molecules, is necessary for effective neurotransmission and synaptic function. A subclass of these adhesion molecules include the cadherins, a group of $\mathrm{Ca}^{2+}$-dependent glycoproteins which link the actin filament network associated with synaptic membranes. $\mathrm{N}$-cadherin contributes to the structural and functional organization of the synaptic complex by ensuring this adhesion and close junction of pre and postsynaptic elements necessary for efficient synaptic communication and plasticity [81]. Thus, a $\mathrm{Ca}^{2}$
${ }^{+}$-mediated disruption in cadherin function would further disrupt synaptic stability, in addition to the well-described loss of mushroom spines through actin destabilization [2].

Reduced vesicle stores and synaptic depression at the single neuron level can contribute to broader hippocampal network defects. VSD imaging has previously been used to show that abnormal excitability may be an important contributor to early-stage AD pathophysiology [99]. To our knowledge, the current study is the first use of VSD imaging to examine how the hippocampal CA1 network is affected in $A D$. In the $3 x T g-A D$ mice, we expected that the increased RyR-evoked $\mathrm{Ca}^{2+}$ would lead to enhanced $\mathrm{Ca}^{2+}$-activated $\mathrm{K}^{+}$channel activation [28] and thus decreased neuronal excitability manifesting as spatially and temporally blunted CA1 depolarization. Our results revealed that network plasticity differences between NonTg and 3xTg-AD mice at this age were restricted to a surprising location: the $\mathrm{SO}$ subfield of CA1. The SO is largely comprised of the basilar dendrites of the CA1 pyramidal cells, and receives a strong input from CA2. This local circuit is important for social learning $[109,110]$, which is relevant in light of recent studies showing a link between increased social activity and increased resilience to developing $\mathrm{AD}[111,112]$. The $\mathrm{SO}$ also contains an important class of interneurons (oriens lacunosum-moleculare or OLM cells), which coordinate cell assemblies and cross frequency coupling, and drive theta oscillations and gate LTP [110]. Thus broader effects on memory encoding may also manifest as a result of CA2-SO network defects. Indeed, the impaired network plasticity in the $\mathrm{SO}$ of 3 month-old 3xTg-AD mice may contribute to the working memory deficits present at this age $[11,12]$. The CA2-SO circuit is also associated with driving socially-related behaviors and learning. In several mouse models of $\mathrm{AD}$, social learning and responses are impaired at an early stage, often prior to overt spatial memory defects [113-117] suggesting that overt disruptions in the CA2-SO circuit precede those within the CA3-CA1 SR Schaffer collateral circuit in AD. This may reflect early selective changes within the CA2-SO circuit which suppress signal propagation and PTP [118] through this hippocampal subfield, such as increased expression of inhibitory GABA A $\alpha 2, \alpha 5$, [119] and $\mathrm{K}_{\mathrm{ATP}}$ channel subunits, as well as GFAP [120]. In addition to upregulated inhibitory mediators within the SO, alternative compensatory mechanisms may be recruited concurrently within the CA3-CA1 SR synapse which augment synaptic signaling, such as increased nNOS and NO [29]. Notably, the CA3-CA1 SR circuit appears relatively functional in $3 \times \mathrm{Tg}-\mathrm{AD}$ mice at $3-4$ months of age, as does LTP expression and the behaviors it supports such as spatial learning performance [6, 45]. 
Future studies will examine dendritic $\mathrm{Ca}^{2+}$ signaling and synaptic plasticity in the SO of CA1 in detail, with the expectation that significant plasticity deficits will be observed in $\mathrm{AD}$ mice at this age, thus exposing a localized vulnerability within hippocampal subfields.

Regarding the use of the 3xTg-AD mouse model, concerns have been expressed about the consistency of the pathological phenotype across colonies, with delays in the amyloid and tau phenotype anecdotally reported. While we are aware of these issues, we have measured consistent responses for over a decade in this mouse model which may reflect the knock-in of the human mutant presenilin gene (which replaces the murine presenilin 1 gene, and is thus expressed under the endogenous murine promoter) rather than the transgenic expression of mutant tau and APP under exogenous promotors such as Thy1 [17, 29]; current study. As a matter of scientific practice, it is important to validate findings across mouse models to confirm that underlying mechanisms are representative of a pathological feature and not an artifact within a single mouse model. Thus, to extend our findings beyond the 3xTg-AD model, we have replicated the fundamental experimental findings and/or identified existing comparable studies using mouse models expressing different complements of $\mathrm{AD}$-associated transgenes or knock-in approaches. For example, in the TgCRND8 model (APP KM670/671NL + V717F), we demonstrate similar patterns of upregulated RyR-evoked $\mathrm{Ca}^{2+}$ release and spike-evoked $\mathrm{Ca}^{2+}$ responses in hippocampal neurons as the $3 \mathrm{xTg}-\mathrm{AD}$ mouse, and a marked suppression of PTP and E-LTP in the PS1/APP ( $\left.\mathrm{APP}_{\mathrm{SWE}} / \mathrm{PS}_{\mathrm{M} 146 \mathrm{~V}}\right)$ models (Additional file 1: Figure S1). The pathogenic ER $\mathrm{Ca}^{2+}$ dyshomeostasis component of $\mathrm{AD}$ has been consistently demonstrated over many years across numerous $\mathrm{AD}$ mouse models including the PS1 $1_{\mathrm{M} 146 \mathrm{~V}} \mathrm{KI}[17,111]$, PS1/APP $\left(\mathrm{APP}_{\mathrm{SWE}} /\right.$ $\left.\mathrm{PS}_{\mathrm{M} 146 \mathrm{~V}}\right)$ [112], PS1/APP (C57BL/6-SJLF1-APP+/-/ C57BL/6-D2F1-PS1+/-; 113) and Tg2576 [114] among others $[15,22]$. Furthermore, human cells obtained from AD patients demonstrate similar $\mathrm{Ca}^{2+}$ signaling abnormalities [20] and RyR dyshomeostasis is identified in non-human primates with AD-like pathology [115]. Reversal of calcium dysregulation and related AD pathology with RyR negative allosteric modulators has been demonstrated in two PS1/APP lines $\left(\mathrm{APP}_{\mathrm{SWE}} / \mathrm{PS}_{\mathrm{M} 146 \mathrm{~V}}\right.$, 59; C57BL/6-SJLF1-APP+/-/C57BL/6-D2F1-PS1+/-; 113), $\operatorname{Tg} 2576$ [114], and $\mathrm{PS}_{\mathrm{M} 146 \mathrm{VI}} \mathrm{KI}$ mice [17]; and the restoration of normal $\mathrm{Ca}^{2+}$ signaling results in reduced amyloid and tau pathology, normalized synaptic transmission and plasticity, and improved cognitive function [59, 113, 114, 116, 117]. Additional pathogenic $\mathrm{Ca}^{2+}$-mediated features that are well-characterized in $3 \times \mathrm{Tg}-\mathrm{AD}$ mice are also detailed in other AD mouse models. For example, increased $\mathrm{Ca}^{2+}$-activated $\mathrm{K}^{+}$ channel activity driven by upregulated $\mathrm{RyR}-\mathrm{Ca}^{2+}[28]$ is verified in the TgCRND8 model along with its effects on neurotransmission and neuronal excitability $[118,119]$. The increase in the frequency of spontaneous neurotransmitter vesicle release at the CA3-CA1 synapse has been replicated in two additional lines of $\mathrm{AD}$ mice $[59,113]$. The increased nNOS in 3xTg-AD mice, driven by RyR-evoked calcium release [29], is similarly upregulated in the TgCRND8 model [120]. Thus, upon this background of consistently reported ER $\mathrm{Ca}^{2+}$ dysregulation, increased frequency of $\mathrm{Ca}^{2}$ ${ }^{+}$-dependent vesicle release, synaptic depression, and altered membrane properties identified in several mouse models of $\mathrm{AD}$ across time, as well as human cells and primates, we feel there is low risk in attributing our findings to a mouse-line specific artifact. It is more probable that the synaptic and physiological deficits we report are a pathological consequence of altered $\mathrm{Ca}^{2+}$ homeostasis that is integral to the $\mathrm{AD}$ disease process.

\section{Conclusions}

In summary, we reveal a sequence of novel synaptic defects in early-stage AD mice that have far-reaching implications for synaptic plasticity encoding and memory formation. Particularly significant is the reduction in active neurotransmitter vesicle stores in CA3 terminals that is associated with STP defects. We show the CA1 SO subfield is particularly vulnerable, thus bringing attention to a hippocampal circuit associated with social memory. Abnormally high synaptically-generated $\mathrm{Ca}^{2+}$ in dendritic spines generated during the tetanus and further increased through STP stages suggests a form of maladaptive meta-plasticity impacting functions central to memory formation and stabilization. These early structural and functional synaptic defects are likely linked to core mechanisms of memory loss in later AD stages.

\section{Additional file}

\footnotetext{
Additional file 1: Figure S1. Additional AD mouse models demonstrate abnormal RyR-specific $\mathrm{Ca}^{2+}$ release and suppressed STP. (A) Bar graph shows peak evoked $\mathrm{Ca}^{2+}$ responses from TgCRND8 +/- mice (gray) and litter mate controls (black) from either RyR-sensitive ER stores (left, t $(1,8)=2.37$; $p<0.05)$, or from voltage-gated $\mathrm{Ca}^{2+}$ channels activated by a train of action potentials (right, $p>0.05$ ). ${ }^{*}=$ significantly different from littermate control. (B) Short-term plasticity such as PTP and E-LTP are disrupted in the APP SWE $_{\text {I }}$ $P S 1_{\text {M146V }}$ mouse model (gray squares, $n=5$ ), as it is in the $3 \times \mathrm{Tg}-\mathrm{AD}$ (black circles, $n=6$ ), compared to background strain NonTg controls. Averaged PTP and E-LTP fEPSP slope values from controls are shown with a dashed line over those epochs to allow for visual clarity. Figure S2. Relative increases in synaptically-evoked $\mathrm{Ca}^{2+}$ responses during plasticity epochs. (A). Dendritic $\mathrm{Ca}^{2+}$ responses during the tetanus, PTP, and E-LTP phases indicated as the $\%$ increase over the $30 \mathrm{~Hz}$ baseline response for each mouse model. These percentages were calculated from the raw data responses as shown in Fig. 4. (B). From the same raw data series, the bar
} 
graphs show the fold-increase in the synaptically-evoked $\mathrm{Ca}^{2+}$ response from the 3xTg-AD mice relative to the response from the NonTg response during each epoch (baseline, tetanus, PTP, E-LTP). (PDF 305 kb)

\section{Abbreviations}

3XTg-AD: triple transgenic AD mouse model; aCSF: artificial cerebrospinal fluid; AD: Alzheimer's disease; AP: action potential; APP: amyloid precursor protein; CA1: Cornu Ammonis area 1; CA2: Cornu Ammonis area 2; $\mathrm{Ca}^{2}$ ${ }^{+}$: calcium; CA3: Cornu Ammonis area 3; CICR: calcium-induced calcium release; CMOS: Complementary metal-oxide-semiconductor; E-LTP: early long term potentiation; EM: electron microscopy; EPSP: excitatory post-synaptic potential; ER: endoplasmic reticulum; FAD: familial Alzheimer's disease; fEPSP: field excitatory post-synaptic potential; $I P_{3} R$ : inositol triphosphate; IR-DIC: infrared differential interference contrast; ISI: interspike interval; LFP: local field potential; LTP: long term potentiation; LY: Lucifer Yellow; NonTg: non transgenic; PBS: phosphate-buffered saline; PCL: pyramidal cell layer; PPF: paired pulse facilitation; PPR: paired pulse ratio; PS: presenilin; PS-1: presenilin-1; PSD: postsynaptic density; PTP: post-tetanic potentiation; RyR: ryanodine receptor; Ryx: Ryanodex; SCS: sucrose cutting solution; SEPSP: spontaneous excitatory post-synaptic potential; SO: stratum oriens; SP: stratum pyramidale; SR: stratum radiatum; STP: short term plasticity; Tau: tau protein; VSD: voltage-sensitive dye

\section{Acknowledgements}

Funding sources were an RFUMS Internal Pilot Award (G.E.S. and W.N.F.), Alzheimer's Association IIRG award (G.E.S.) and NIH R01-AG030205 (G.E.S.). We thank Christopher Brandon, Ph.D. and Susan Weirsema for contributing to the EM study.

\section{Funding}

Funding sources supporting this study were an RFUMS Internal Pilot Award (G.E.S. and W.N.F.), Alzheimer's Association IIRG award (G.E.S.) and NIH R01AG030205 (G.E.S.).

\section{Availability of data and materials}

The data used in this study are available from the corresponding author upon reasonable request.

\section{Authors' contributions}

SC conducted the electrophysiological and calcium imaging experiments, analyzed data, and wrote parts of the manuscript. EH conducted and analyzed the voltage-sensitive dye experiments, and wrote aspects of the paper. DC conducted the spine morphology studies and analyzed data with CS and NK; RH and SR assisted with and analyzed the EM data. SM conducted the immunohistochemistry experiments, generated figures, and wrote aspects of the paper. FS and BV conducted the EM experiments. DP assisted with the immunohistochemistry oversaw confocal microscopy, and generation of figures. AW assisted with the electrophysiology design and analysis, and supervised SC. WF oversaw the design of the network propagation studies, contributed to the writing of the manuscript, and supervised EH. GS oversaw the design and execution of the electrophysiology and calcium imaging experiments, and the synaptic morphology studies, and was a major contributor to the writing of the manuscript. All authors read and approved the final manuscript.

\section{Ethics approval and consent to participate}

Not applicable.

\section{Consent for publication}

Not applicable.

\section{Competing interests}

The authors declare that they have no competing interests.

\section{Publisher's Note}

Springer Nature remains neutral with regard to jurisdictional claims in published maps and institutional affiliations.

\section{Author details}

'Department of Neuroscience, The Chicago Medical School; The Center for Neurodegenerative Disease and Therapeutics, Rosalind Franklin University of Medicine and Science, 3333 Green Bay Rd, North Chicago, IL 60064, USA.
2Department of Cell Biology and Anatomy, The Chicago Medical School; Center for Brain Function and Repair, Rosalind Franklin University of Medicine and Science, 3333 Green Bay Rd, North Chicago, IL 60064, USA. ${ }^{3}$ Electron Microscopy Center, RFUMS, North Chicago, IL 60064, USA.

Received: 30 August 2018 Accepted: 13 January 2019

Published online: 22 January 2019

\section{References}

1. Briggs CA, Chakroborty S, Stutzmann GE. Emerging pathways driving early synaptic pathology in Alzheimer's disease. Biochem Biophys Res Commun. 2017:483(4):988-97 Epub 2016/09/24.

2. Chakroborty S, Stutzmann GE. Early calcium dysregulation in Alzheimer's disease: setting the stage for synaptic dysfunction. Sci China Life Sci. 2011;54(8):752-62.

3. Scheff SW, Price DA, Schmitt FA, DeKosky ST, Mufson EJ. Synaptic alterations in CA1 in mild Alzheimer disease and mild cognitive impairment. Neurology. 2007;68(18):1501-8 Epub 2007/05/02

4. Terry RD, Masliah E, Salmon DP, Butters N, DeTeresa R, Hill R, et al. Physical basis of cognitive alterations in Alzheimer's disease: synapse loss is the major correlate of cognitive impairment. Ann Neurol. 1991;30(4):572-80 Epub 1991/10/01.

5. Marchetti C, Marie H. Hippocampal synaptic plasticity in Alzheimer's disease: what have we learned so far from transgenic models? Rev Neurosci. 2011; 22(4):373-402 Epub 2011/07/08.

6. Oddo S, Caccamo A, Shepherd JD, Murphy MP, Golde TE, Kayed R, et al. Triple-transgenic model of Alzheimer's disease with plaques and tangles: intracellular Abeta and synaptic dysfunction. Neuron. 2003;39(3):409-21 Epub 2003/08/05.

7. Frey U, Morris RG. Synaptic tagging and long-term potentiation. Nature. 1997;385(6616):533-6 Epub 1997/02/06

8. Li Q, Rothkegel M, Xiao ZC, Abraham WC, Korte M, Sajikumar S. Making synapses strong: metaplasticity prolongs associativity of long-term memory by switching synaptic tag mechanisms. Cereb Cortex (New York, NY: 1991). 2014;24(2):353-63 Epub 2012/10/11

9. Moncada D, Ballarini F, Viola H. Behavioral tagging: a translation of the synaptic tagging and capture hypothesis. Neural plasticity. 2015;2015: 650780 Epub 2015/09/18.

10. Wang CC, Weyrer C, Paturu M, Fioravante D, Regehr WG. Calcium-dependent protein kinase $\mathrm{C}$ is not required for post-tetanic potentiation at the hippocampal CA3 to CA1 synapse. J Neurosci. 2016;36(24):6393-402 Epub 2016/06/17.

11. Clark JK, Furgerson M, Crystal JD, Fechheimer M, Furukawa R, Wagner JJ. Alterations in synaptic plasticity coincide with deficits in spatial working memory in presymptomatic 3xTg-AD mice. Neurobiol Learn Mem. 2015;125: 152-62 Epub 2015/09/20.

12. Stevens LM, Brown RE. Reference and working memory deficits in the 3xTgAD mouse between 2 and 15-months of age: a cross-sectional study. Behav Brain Res. 2015;278:496-505 Epub 2014/12/03.

13. Bezprozvanny I, Mattson MP. Neuronal calcium mishandling and the pathogenesis of Alzheimer's disease. Trends Neurosci. 2008;31(9):454-63 Epub 2008/08/05

14. Bruno AM, Huang JY, Bennett DA, Marr RA, Hastings ML, Stutzmann GE. Altered ryanodine receptor expression in mild cognitive impairment and Alzheimer's disease. Neurobiol Aging. 2012;33(5):1001 e1-6 Epub 201 1/05/03.

15. Del Prete D, Checler F, Chami M. Ryanodine receptors: physiological function and deregulation in Alzheimer disease. Mol Neurodegener. 2014;9:21 Epub 2014/06/07.

16. Stutzmann GE, Caccamo A, LaFerla FM, Parker I. Dysregulated IP3 signaling in cortical neurons of knock-in mice expressing an Alzheimer's-linked mutation in presenilin1 results in exaggerated $\mathrm{Ca} 2+$ signals and altered membrane excitability. J Neurosci. 2004;24(2):508-13 Epub 2004/01/16.

17. Stutzmann GE, Smith I, Caccamo A, Oddo S, LaFerla FM, Parker I. Enhanced ryanodine receptor recruitment contributes to Ca2+ disruptions in young, adult, and aged Alzheimer's disease mice. J Neurosci. 2006;26(19):5180-9.

18. Etcheberrigaray R, Hirashima N, Nee L, Prince J, Govoni S, Racchi M, et al. Calcium responses in fibroblasts from asymptomatic members of Alzheimer's disease families. Neurobiol Dis. 1998;5(1):37-45 Epub 1998/08/14

19. Ito E, Oka K, Etcheberrigaray R, Nelson TJ, McPhie DL, Tofel-Grehl B, et al. Internal Ca2+ mobilization is altered in fibroblasts from patients with Alzheimer disease. Proc Natl Acad Sci U S A. 1994;91(2):534-8 Epub 1994/01/18.

20. Nelson O, Supnet C, Liu H, Bezprozvanny I. Familial Alzheimer's disease mutations in presenilins: effects on endoplasmic reticulum calcium 
homeostasis and correlation with clinical phenotypes. J Alzheim Dis. 2010; 21(3):781-93 Epub 2010/07/17.

21. Goussakov I, Miller MB, Stutzmann GE. NMDA-mediated ca(2+) influx drives aberrant ryanodine receptor activation in dendrites of young Alzheimer's disease mice. J Neurosci. 2010;30(36):12128-37 Epub 2010/09/10.

22. Stutzmann GE. The pathogenesis of Alzheimers disease-is it a lifelong "Calciumopathy"? Neuroscientist. 2007;13(5):546-59.

23. Higley MJ, Sabatini BL. Calcium signaling in dendrites and spines: practical and functional considerations. Neuron. 2008;59(6):902-13 Epub 2008/09/27.

24. Koffie RM, Meyer-Luehmann M, Hashimoto T, Adams KW, Mielke ML, GarciaAlloza M, et al. Oligomeric amyloid beta associates with postsynaptic densities and correlates with excitatory synapse loss near senile plaques. Proc Natl Acad Sci U S A. 2009;106(10):4012-7 Epub 2009/02/21.

25. Kuchibhotla KV, Goldman ST, Lattarulo CR, Wu HY, Hyman BT, Bacskai BJ. Abeta plaques lead to aberrant regulation of calcium homeostasis in vivo resulting in structural and functional disruption of neuronal networks. Neuron. 2008;59(2):214-25 Epub 2008/08/01.

26. Llano I, Gonzalez J, Caputo C, Lai FA, Blayney LM, Tan YP, et al. Presynaptic calcium stores underlie large-amplitude miniature IPSCs and spontaneous calcium transients. Nat Neurosci. 2000;3(12):1256-65 Epub 2000/12/02.

27. Berridge MJ. Dysregulation of neural calcium signaling in Alzheimer disease, bipolar disorder and schizophrenia. Prion. 2013;7(1):2-13 Epub 2012/08/17.

28. Chakroborty S, Kim J, Schneider C, Jacobson C, Molgó J, Stutzmann GE. Early presynaptic and postsynaptic calcium signaling abnormalities mask underlying synaptic depression in presymptomatic Alzheimer's disease mice. J Neurosci. 2012;32(24):8341-53.

29. Chakroborty S, Kim J, Schneider C, West AR, Stutzmann GE. Nitric oxide signaling is recruited as a compensatory mechanism for sustaining synaptic plasticity in Alzheimer's disease mice. J Neurosci. 2015;35(17):6893-902.

30. Popugaeva E, Bezprozvanny I. Can the calcium hypothesis explain synaptic loss in Alzheimer's disease? Neurodegener Dis. 2014;13(2-3):139-41 Epub 2013/10/02.

31. Zhang H, Liu J, Sun S, Pchitskaya E, Popugaeva E, Bezprozvanny I. Calcium signaling, excitability, and synaptic plasticity defects in a mouse model of Alzheimer's disease. J Alzheim Dis. 2015;45(2):561-80 Epub 2015/01/16

32. Eliot LS, Kandel ER, Hawkins RD. Modulation of spontaneous transmitter release during depression and posttetanic potentiation of Aplysia sensorymotor neuron synapses isolated in culture. J Neurosci. 1994;14(5 Pt 2):328092 Epub 1994/05/01.

33. Wu HY, Hudry E, Hashimoto T, Kuchibhotla K, Rozkalne A, Fan Z, et al. Amyloid beta induces the morphological neurodegenerative triad of spine loss, dendritic simplification, and neuritic dystrophies through calcineurin activation. J Neurosci. 2010;30(7):2636-49 Epub 2010/02/19.

34. Xue L, Wu LG. Post-tetanic potentiation is caused by two signalling mechanisms affecting quantal size and quantal content. J Physiol. 2010; 588(Pt 24):4987-94 Epub 2010/11/03.

35. Takami K, Terai K, Matsuo A, Walker DG, McGeer PL. Expression of presenilin1 and -2 mRNAs in rat and Alzheimer's disease brains. Brain Res. 1997; 748(1-2):122-30 Epub 1997/02/14.

36. Stutzmann GE, Parker I. Dynamic multiphoton imaging: a live view from cells to systems. Physiology (Bethesda, Md). 2005;20:15-21 Epub 2005/01/18.

37. Harris KM, Jensen FE, Tsao B. Three-dimensional structure of dendritic spines and synapses in rat hippocampus (CA1) at postnatal day 15 and adult ages: implications for the maturation of synaptic physiology and long-term potentiation. J Neurosci. 1992;12(7):2685-705 Epub 1992/07/01.

38. Rademacher DJ, Rosenkranz JA, Morshedi MM, Sullivan EM, Meredith GE. Amphetamine-associated contextual learning is accompanied by structural and functional plasticity in the basolateral amygdala. J Neurosci. 2010;30(13): 4676-86 Epub 2010/04/02.

39. Takacs VT, Klausberger T, Somogyi P, Freund TF, Gulyas Al. Extrinsic and local glutamatergic inputs of the rat hippocampal CA1 area differentially innervate pyramidal cells and interneurons. Hippocampus. 2012;22(6):137991 Epub 2011/10/01

40. Ero CGM-O, Keller D, Markram HA. Cell atlas for the mouse brain. Front Neuroinformatics. 2018:12:1-16.

41. Miranda R, Nudel U, Laroche S, Vaillend C. Altered presynaptic ultrastructure in excitatory hippocampal synapses of mice lacking dystrophins Dp427 or Dp71. Neurobiol Dis. 2011;43(1):134-41 Epub 2011/03/15.

42. Filbert MLEBG. Neuroprotection for nerve agent-induced brain damage by blocking delayed calcium overload: a review. J Med CBR Def. 2005;3:21.
43. Dumitriu D, Hao J, Hara Y, Kaufmann J, Janssen WG, Lou W, et al. Selective changes in thin spine density and morphology in monkey prefrontal cortex correlate with aging-related cognitive impairment. J Neurosci. 2010;30(22): 7507-15 Epub 2010/06/04.

44. Meredith GE, Agolia R, Arts MP, Groenewegen HJ, Zahm DS. Morphological differences between projection neurons of the core and shell in the nucleus accumbens of the rat. Neuroscience. 1992;50(1):149-62 Epub 1992/09/01.

45. Chakroborty S, Goussakov I, Miller MB, Stutzmann GE. Deviant ryanodine receptor-mediated calcium release resets synaptic homeostasis in presymptomatic 3xTg-AD mice. J Neurosci. 2009;29(30):9458-70.

46. Decker H, Jurgensen S, Adrover MF, Brito-Moreira J, Bomfim TR, Klein WL, et al. N-methyl-D-aspartate receptors are required for synaptic targeting of Alzheimer's toxic amyloid-beta peptide oligomers. J Neurochem. 2010; 115(6):1520-9 Epub 2010/10/19.

47. Hooper C, Markevich V, Plattner F, Killick R, Schofield E, Engel T, et al. Glycogen synthase kinase-3 inhibition is integral to long-term potentiation. Eur J Neurosci. 2007:25(1):81-6 Epub 2007/01/24

48. Seabrook GR, Smith DW, Bowery BJ, Easter A, Reynolds T, Fitzjohn SM, et al. Mechanisms contributing to the deficits in hippocampal synaptic plasticity in mice lacking amyloid precursor protein. Neuropharmacology. 1999;38(3): 349-59 Epub 1999/04/29.

49. Citri A, Malenka RC. Synaptic plasticity: multiple forms, functions, and mechanisms. Neuropsychopharmacology. 2008;33(1):18-41 Epub 2007/08/31.

50. Goldman-Rakic PS. Cellular basis of working memory. Neuron. 1995;14(3): 477-85 Epub 1995/03/01.

51. Hansel D, Mato G. Short-term plasticity explains irregular persistent activity in working memory tasks. J Neurosci. 2013;33(1):133-49 Epub 2013/01/04

52. Hiratani N, Fukai T. Interplay between short- and long-term plasticity in cellassembly formation. PLoS One. 2014;9(7):e101535 Epub 2014/07/10.

53. Fioravante D, Regehr WG. Short-term forms of presynaptic plasticity. Curr Opin Neurobiol. 2011;21(2):269-74 Epub 2011/03/01.

54. Wojtowicz JM, Marin L, Atwood HL. Activity-induced changes in synaptic release sites at the crayfish neuromuscular junction. J Neurosci. 1994;14(6): 3688-703 Epub 1994/06/01.

55. Zucker RS, Regehr WG. Short-term synaptic plasticity. Annu Rev Physiol. 2002;64:355-405 Epub 2002/02/05.

56. Lisman J, Raghavachari S. A unified model of the presynaptic and postsynaptic changes during LTP at CA1 synapses. Science's STKE: signal transduction knowledge environment. 2006;2006(356):re11. Epub 2006/10/13.

57. Malinow R, Malenka RC. AMPA receptor trafficking and synaptic plasticity. Annu Rev Neurosci. 2002;25:103-26 Epub 2002/06/08.

58. Wikstrom MA, Matthews P, Roberts D, Collingridge GL, Bortolotto ZA. Parallel kinase cascades are involved in the induction of LTP at hippocampal CA1 synapses. Neuropharmacology. 2003;45(6):828-36 Epub 2003/10/08.

59. Davies SN, Lester RA, Reymann KG, Collingridge GL. Temporally distinct preand post-synaptic mechanisms maintain long-term potentiation. Nature. 1989;338(6215):500-3 Epub 1989/04/06

60. Frey $U$, Huang $Y Y$, Kandel ER. Effects of CAMP simulate a late stage of LTP in hippocampal CA1 neurons. Science. 1993;260(5114):1661-4 Epub 1993/06/11.

61. Chakroborty S, Briggs C, Miller MB, Goussakov I, Schneider C, Kim J, et al. Stabilizing ER Ca2+ channel function as an early preventative strategy for Alzheimer's disease. PLoS One. 2012;7(12):e52056.

62. Hamada K, Terauchi A, Nakamura K, Higo T, Nukina N, Matsumoto N, et al. Aberrant calcium signaling by transglutaminase-mediated posttranslational modification of inositol 1,4,5-trisphosphate receptors. Proc Natl Acad Sci. 2014;111(38):E3966-E75

63. Pchitskaya E, Popugaeva E, Bezprozvanny I. Calcium signaling and molecular mechanisms underlying neurodegenerative diseases. Cell Calcium. 2017.

64. Weber JT. Altered calcium signaling following traumatic brain injury. Front Pharmacol. 2012;3:60 Epub 2012/04/21.

65. Kavalali ET. The mechanisms and functions of spontaneous neurotransmitter release. Nat Rev Neurosci. 2015;16(1):5-16 Epub 2014/12/20.

66. Lee JS, Ho WK, Lee SH. Post-tetanic increase in the fast-releasing synaptic vesicle pool at the expense of the slowly releasing pool. J Gen Physiol. 2010:136(3):259-72 Epub 2010/09/02.

67. Brager DH, Cai X, Thompson SM. Activity-dependent activation of presynaptic protein kinase $\mathrm{C}$ mediates post-tetanic potentiation. Nat Neurosci. 2003;6(6):551-2 Epub 2003/05/20.

68. Habets RL, Borst JG. Post-tetanic potentiation in the rat calyx of held synapse. J Physiol. 2005;564(Pt 1):173-87 Epub 2005/02/08. 
69. Korogod N, Lou X, Schneggenburger R. Presynaptic Ca2+ requirements and developmental regulation of posttetanic potentiation at the calyx of held. J Neurosci. 2005;25(21):5127-37 Epub 2005/05/27.

70. Collin T, Marty A, Llano I. Presynaptic calcium stores and synaptic transmission. Curr Opin Neurobiol. 2005;15(3):275-81 Epub 2005/05/28.

71. Emptage NJ, Reid CA, Fine A. Calcium stores in hippocampal synaptic boutons mediate short-term plasticity, store-operated Ca2+ entry, and spontaneous transmitter release. Neuron. 2001;29(1):197-208 Epub 2001/02/22.

72. Shakiryanova D, Klose MK, Zhou Y, Gu T, Deitcher DL, Atwood HL, et al. Presynaptic ryanodine receptor-activated calmodulin kinase II increases vesicle mobility and potentiates neuropeptide release. J Neurosci. 2007; 27(29):7799-806 Epub 2007/07/20.

73. Shakiryanova D, Morimoto T, Zhou C, Chouhan AK, Sigrist SJ, Nose A, et al. Differential control of presynaptic CaMKII activation and translocation to active zones. J Neurosci. 2011:31(25):9093-100 Epub 2011/06/24.

74. Bardo S, Cavazzini MG, Emptage N. The role of the endoplasmic reticulum $\mathrm{Ca} 2+$ store in the plasticity of central neurons. Trends Pharmacol Sci. 2006; 27(2):78-84 Epub 2006/01/18.

75. Fitzjohn SM, Collingridge GL. Calcium stores and synaptic plasticity. Cell Calcium. 2002;32(5-6):405-11 Epub 2003/01/25.

76. Malenka RC, Bear MF. LTP and LTD: an embarrassment of riches. Neuron. 2004:44(1):5-21 Epub 2004/09/29.

77. Berridge MJ, Bootman MD, Roderick HL. Calcium signalling: dynamics, homeostasis and remodelling. Nat Rev Mol Cell Biol. 2003;4(7):517-29 Epub 2003/07/03.

78. Bloodgood BL, Sabatini BL. Ca(2+) signaling in dendritic spines. Curr Opin Neurobiol. 2007:17(3):345-51 Epub 2007/04/25.

79. Rochefort NL, Konnerth A. Dendritic spines: from structure to in vivo function. EMBO Rep. 2012;13(8):699-708 Epub 2012/07/14.

80. Arikkath J, Reichardt LF. Cadherins and catenins at synapses: roles in synaptogenesis and synaptic plasticity. Trends Neurosci. 2008;31(9):487-94 Epub 2008/08/08.

81. Bamji SX. Cadherins: actin with the cytoskeleton to form synapses. Neuron 2005;47(2):175-8 Epub 2005/07/26

82. Mendez P, De Roo M, Poglia L, Klauser P, Muller D. N-cadherin mediates plasticity-induced long-term spine stabilization. J Cell Biol. 2010;189(3): 589-600 Epub 2010/05/05.

83. Cingolani LA, Goda Y. Actin in action: the interplay between the actin cytoskeleton and synaptic efficacy. Nat Rev Neurosci. 2008;9(5):344-56 Epub 2008/04/22.

84. Kasai H, Fukuda M, Watanabe S, Hayashi-Takagi A, Noguchi J. Structural dynamics of dendritic spines in memory and cognition. Trends Neurosci. 2010;33(3):121-9 Epub 2010/02/09.

85. Dillon C, Goda Y. The actin cytoskeleton: integrating form and function at the synapse. Annu Rev Neurosci. 2005;28:25-55 Epub 2005/07/21.

86. Merriam EB, Millette M, Lumbard DC, Saengsawang W, Fothergill T, Hu X, et al. Synaptic regulation of microtubule dynamics in dendritic spines by calcium, F-actin, and drebrin. J Neurosci. 2013;33(42):16471-82 Epub 2013/10/18.

87. Oertner TG, Matus A. Calcium regulation of actin dynamics in dendritic spines. Cell Calcium. 2005;37(5):477-82 Epub 2005/04/12.

88. Perez-Cruz C, Nolte MW, van Gaalen MM, Rustay NR, Termont A, Tanghe A, et al. Reduced spine density in specific regions of CA1 pyramidal neurons in two transgenic mouse models of Alzheimer's disease. J Neurosci. 2011; 31(10):3926-34 Epub 2011/03/11.

89. Spires TL, Meyer-Luehmann M, Stern EA, McLean PJ, Skoch J, Nguyen PT, et al. Dendritic spine abnormalities in amyloid precursor protein transgenic mice demonstrated by gene transfer and intravital multiphoton microscopy. J Neurosci. 2005;25(31):7278-87 Epub 2005/08/05.

90. Bourne J, Harris KM. Do thin spines learn to be mushroom spines that remember? Curr Opin Neurobiol. 2007;17(3):381-6 Epub 2007/05/15.

91. Christian DT, Wang X, Chen EL, Sehgal LK, Ghassemlou MN, Miao JJ, et al. Dynamic alterations of rat nucleus Accumbens dendritic spines over 2 months of abstinence from extended-access cocaine self-administration. Neuropsychopharmacology. 2017:42(3):748-56 Epub 2016/08/25.

92. Dumitriu D, Rodriguez A, Morrison JH. High-throughput, detailed, cellspecific neuroanatomy of dendritic spines using microinjection and confocal microscopy. Nat Protoc. 2011;6(9):1391-411 Epub 2011/09/03.

93. Yu W, Cook C, Sauter C, Kuriyama R, Kaplan PL, Baas PW. Depletion of a microtubule-associated motor protein induces the loss of dendritic identity. J Neurosci. 2000;20(15):5782-91 Epub 2000/07/26.
94. Zhang H, Wu L, Pchitskaya E, Zakharova O, Saito T, Saido T, et al. Neuronal store-operated calcium entry and mushroom spine loss in amyloid precursor protein Knock-in mouse model of Alzheimer's disease. J Neurosci. 2015;35(39):13275-86 Epub 2015/10/02.

95. Coulter DA, Yue C, Ang CW, Weissinger F, Goldberg E, Hsu FC, et al. Hippocampal microcircuit dynamics probed using optical imaging approaches. J Physiol. 2011;589(Pt 8):1893-903 Epub 2011/01/13.

96. Stepan J, Dine J, Eder M. Functional optical probing of the hippocampal trisynaptic circuit in vitro: network dynamics, filter properties, and polysynaptic induction of CA1 LTP. Front Neurosci. 2015;9:160 Epub 2015/05/23.

97. Tominaga $Y$, Ichikawa M, Tominaga T. Membrane potential response profiles of CA1 pyramidal cells probed with voltage-sensitive dye optical imaging in rat hippocampal slices reveal the impact of GABA(A)-mediated feed-forward inhibition in signal propagation. Neurosci Res. 2009;64(2):152-61 Epub 2009/05/12.

98. Pal I, Kardos J, Dobolyi A, Heja L. Appearance of fast astrocytic component in voltage-sensitive dye imaging of neural activity. Mol Brain. 2015;8:35 Epub 2015/06/06

99. Hazra A, Gu F, Aulakh A, Berridge C, Eriksen JL, Ziburkus J. Inhibitory neuron and hippocampal circuit dysfunction in an aged mouse model of Alzheimer's disease. PLoS One. 2013;8(5):e64318 Epub 2013/05/22.

100. Redondo RL, Morris RG. Making memories last: the synaptic tagging and capture hypothesis. Nat Rev Neurosci. 2011;12(1):17-30 Epub 2010/12/21.

101. Sajikumar S, Li Q, Abraham WC, Xiao ZC. Priming of short-term potentiation and synaptic tagging/capture mechanisms by ryanodine receptor activation in rat hippocampal CA1. Learn Mem (Cold Spring Harbor, NY). 2009;16(3): 178-86 Epub 2009/02/19.

102. Cheung KH, Shineman D, Muller M, Cardenas C, Mei L, Yang J, et al. Mechanism of $\mathrm{Ca} 2+$ disruption in Alzheimer's disease by presenilin regulation of InsP3 receptor channel gating. Neuron. 2008;58(6):871-83 Epub 2008/06/27.

103. Goussakov I, Chakroborty S, Stutzmann GE. Generation of dendritic Ca2+ oscillations as a consequence of altered ryanodine receptor function in $A D$ neurons. Channels (Austin, Tex). 2011;5(1):9-13 Epub 2010/12/09.

104. Bouchard R, Pattarini R, Geiger JD. Presence and functional significance of presynaptic ryanodine receptors. Prog Neurobiol. 2003;69(6):391-418 Epub 2003/07/26.

105. Kuromi H, Kidokoro Y. Two synaptic vesicle pools, vesicle recruitment and replenishment of pools at the Drosophila neuromuscular junction. J Neurocytol. 2003;32(5-8):551-65 Epub 2004/03/23.

106. Deng PY, Sojka D, Klyachko VA. Abnormal presynaptic short-term plasticity and information processing in a mouse model of fragile $X$ syndrome. J Neurosci. 2011;31(30):10971-82 Epub 2011/07/29.

107. Scimemi A, Diamond JS. The number and organization of Ca2+ channels in the active zone shapes neurotransmitter release from Schaffer collateral synapses. J Neurosci. 2012;32(50):18157-76 Epub 2012/12/15.

108. Grigoryan G, Segal M. Ryanodine-mediated conversion of STP to LTP is lacking in synaptopodin-deficient mice. Brain Struct Funct. 2016;221(4): 2393-7 Epub 2015/03/17.

109. Andersen P. The hippocampus book. Oxford: Oxford university press; 2007.

110. Leao RN, Mikulovic S, Leao KE, Munguba H, Gezelius H, Enjin A, et al. OLM interneurons differentially modulate CA3 and entorhinal inputs to hippocampal CA1 neurons. Nat Neurosci. 2012;15(11):1524-30 Epub 2012/10/09.

111. Anme TKY, Shinohara R, Sugisawa Y, Watanabe T, Tokutake K, Mochizuki Y, Morita K, Tomisaki E, Tanaka E, Wu B, Gan-Yadam A, Nanba M, Matsumoto M, Sugita C, Okumura R, Ito S. Social interaction and dementia prevention: six-year follow-up study. J Public Health Front. 2013;2(2):109-13.

112. Mortimer JA, Ding D, Borenstein AR, DeCarli C, Guo Q, Wu Y, et al. Changes in brain volume and cognition in a randomized trial of exercise and social interaction in a community-based sample of non-demented Chinese elders. J Alzheim Dis. 2012;30(4):757-66 Epub 2012/03/28.

113. Bories C, Guitton MJ, Julien C, Tremblay C, Vandal M, Msaid M, et al. Sexdependent alterations in social behaviour and cortical synaptic activity coincide at different ages in a model of Alzheimer's disease. PLoS One. 2012;7(9):e46111 Epub 2012/10/03.

114. Cheng D, Spiro AS, Jenner AM, Garner B, Karl T. Long-term cannabidiol treatment prevents the development of social recognition memory deficits in Alzheimer's disease transgenic mice. J Alzheim Dis. 2014;42(4):1383-96 Epub 2014/07/16.

115. Latif-Hernandez A, Shah D, Craessaerts K, Saido T, Saito T, De Strooper B, et al. Subtle behavioral changes and increased prefrontal-hippocampal 
network synchronicity in APP(NL-G-F) mice before prominent plaque deposition. Behav Brain Res. 2017; Epub 2017/11/22.

116. Olesen LO, Bouzinova EV, Severino M, Sivasaravanaparan M, Hasselstrom JB, Finsen B, et al. Behavioural phenotyping of APPswe/PS1 deltaE9 mice: ageRrelated changes and effect of long-term paroxetine treatment. PLoS One. 2016;11(11):e0165144 Epub 2016/11/05.

117. Plucinska K, Crouch B, Koss D, Robinson L, Siebrecht M, Riedel G, et al. Knock-in of human BACE1 cleaves murine APP and reiterates Alzheimer-like phenotypes. J Neurosci. 2014;34(32):10710-28 Epub 2014/08/08.

118. Zhao J, Li A, Rajsombath M, Dang Y, Selkoe DJ, Li S. Soluble Abeta Oligomers Impair Dipolar Heterodendritic Plasticity by Activation of mGluR in the Hippocampal CA1 Region. iScience. 2018;6:138-50 Epub 2018/09/22.

119. Kwakowsky A, Calvo-Flores Guzman B, Pandya M, Turner C, Waldvogel HJ, Faull RL. GABAA receptor subunit expression changes in the human Alzheimer's disease hippocampus, subiculum, entorhinal cortex and superior temporal gyrus. J Neurochem. 2018;145(5):374-92 Epub 2018/02/28.

120. Griffith CM, Xie MX, Qiu WY, Sharp AA, Ma C, Pan A, et al. Aberrant expression of the pore-forming KATP channel subunit Kir6.2 in hippocampal reactive astrocytes in the 3xTg-AD mouse model and human Alzheimer's disease. Neuroscience. 2016;336:81-101 Epub 2016/09/03.

Ready to submit your research? Choose BMC and benefit from:

- fast, convenient online submission

- thorough peer review by experienced researchers in your field

- rapid publication on acceptance

- support for research data, including large and complex data types

- gold Open Access which fosters wider collaboration and increased citations

- maximum visibility for your research: over $100 \mathrm{M}$ website views per year

At $\mathrm{BMC}$, research is always in progress.

Learn more biomedcentral.com/submissions 